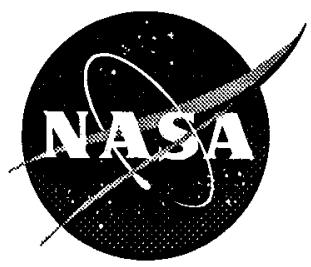

\title{
Full Flight Envelope Direct Thrust Measurement on a Supersonic Aircraft
}

Timothy R. Conners and Robert L. Sims

Dryden Flight Research Center

Edwards, California

National Aeronautics and

Space Administration

Dryden Flight Research Center

Edwards, California 93523-0273 


\section{NOTICE}

Use of trade names or names of manufacturers in this document does not constitute an official endorsement of such products or manufacturers, either expressed or implied, by the National Aeronautics and Space Administration.

Available from the following:

NASA Center for AeroSpace Information (CASI)

7121 Standard Drive

Hanover, MD 21076-1320

(301) 621-0390
National Technical Information Service (NTIS)

5285 Port Royal Road

Springfield, VA 22161-2171

(703) $487-4650$ 


\title{
FULL FLIGHT ENVELOPE DIRECT THRUST MEASUREMENT ON A SUPERSONIC AIRCRAFT
}

\author{
Timothy R. Conners ${ }^{*}$ and Robert L. Sims ${ }^{\dagger}$ \\ NASA Dryden Flight Research Center \\ Edwards, California
}

\begin{abstract}
$\underline{\text { Abstract }}$
Direct thrust measurement using strain gages offers advantages over analytically-based thrust calculation methods. For flight test applications, the direct measurement method typically uses a simpler sensor arrangement and minimal data processing compared to analytical techniques, which normally require costly engine modeling and multisensor arrangements throughout the engine. Conversely, direct thrust measurement has historically produced less than desirable accuracy because of difficulty in mounting and calibrating the strain gages and the inability to account for secondary forces that influence the thrust reading at the engine mounts. Consequently, the strain-gage technique has normally been used for simple engine arrangements and primarily in the subsonic speed range. This paper presents the results of a strain gage-based direct thrust-measurement technique developed by the NASA Dryden Flight Research Center and successfully applied to the full flight envelope of an F-15 aircraft powered by two F100-PW-229 turbofan engines. Measurements have been obtained at quasi-steady-state operating conditions at maximum nonaugmented and maximum augmented power throughout the altitude range of the vehicle and to a maximum speed of Mach 2.0, and are compared against results from two analytically-based thrust calculation methods. The strain-gage installation and calibration processes are also described.
\end{abstract}

\section{$\underline{\text { Nomenclature }}$}

A cross-sectional area, in ${ }^{2}$

ACTIVE Advanced Control Technology for Integrated Vehicles

\footnotetext{
* Aerospace Engineer, Senior Member AIAA

† Aerospace Engineer.

Copyright (C) 1998 by the American Institute of Aeronautics and Astronautics, Inc. No copyright is asserted in the United States under Title 17, U.S. Code. The U.S. Government has a royalty-free license to exercise all rights under the copyright claimed herein for Governmental purposes. All other rights are reserved by the copyright owner.
}

\author{
$F \quad$ force, $\mathrm{lbf}$ \\ g gravitation acceleration constant, \\ $32.2 \mathrm{ft} / \mathrm{sec}^{2}$ \\ IDEEC improved digital electronic engine \\ controller \\ M Mach number \\ $P \quad$ static pressure, $1 b f / i^{2}$ absolute \\ $P_{T} \quad$ total pressure, $\mathrm{lbf} / \mathrm{in}^{2}$ absolute \\ S/MTD Short Takeoff and Landing/Maneuver \\ Technology Demonstrator \\ $T_{T} \quad$ total temperature, ${ }^{\circ} \mathrm{F}$ \\ USAF United States Air Force \\ $V \quad$ velocity, $\mathrm{ft} / \mathrm{sec}$ \\ WACC station-corrected engine mass flow, $\mathrm{lbm} / \mathrm{sec}$ \\ WAT true engine mass flow, $\mathrm{lbm} / \mathrm{sec}$ \\ $\sigma \quad$ standard deviation \\ Engine Stations \\ 0 free stream (ambient) \\ 2 engine-inlet plane

\section{Introduction}

For flight-testing applications, direct thrust measurement using strain gages offers advantages over traditional, model-based analytical thrust calculation methods. ${ }^{1}$ Depending on the objectives of the flight test program and resources available to the test facility, these advantages may permit in-flight thrust measurement that would not be feasible otherwise.

Depending upon the application, the direct thrust-measurement method can be less complex and costly to implement compared to model-based techniques. The strain-gage sensor arrangement is typically less cumbersome and costly to procure, install, and calibrate than the multisensor package required to collect the input data for traditional analytically-based 
thrust models, particularly if a wind-tunnel calibration of the analytical model to the specific test engine would otherwise be required prior to test program commencement. The computer models are an additional requirement to which the direct measurement method is not subject. These models can be very costly for the end user to procure and maintain, if the models even exist. If the models do not exist and therefore need to be developed for the engine in question, then the cost for procurement can easily be prohibitive.

Although the typical in-flight thrust model has limited self-tuning capability, if the engine has strayed far from an average baseline state (for instance, because of significant deterioration or damage), then the calculation accuracy will suffer. Because the strain gage-based technique measures thrust directly, the technique is not subject to this type of error.

An in-flight thrust computer program is normally capable of modeling only steady-state or quasisteady-state engine operation. A computer program typically assumes thermal equilibrium and stoichiometric fuel-to-air ratios that do not account for engine acceleration or deceleration schedules, and can be further limited by the responsiveness of the input parameters. ${ }^{2}$ The strain-gage technique, however, is not hindered by modeling and input measurement rate limitation to the same extent. Because of the inherent high dynamic response of strain gages, the direct measurement technique is superior to model-based techniques when dynamic thrust measurement is a requirement. Not having the computational burden of the analytical methods, the direct thrust-measurement technique is better suited for real-time monitoring applications as well.

Although the direct thrust-measurement technique has several advantages, careful attention must be paid to the design and calibration of the system in order to reduce measurement error and calibration drift. Misconceptions and misapplications have hampered the widespread use of the direct thrust-measurement technique, and the method has historically produced less than desirable accuracy. Without careful installation and calibration of the strain gages, the accuracy of the direct measurement technique will be inferior to the model-based method.

Proper design of a direct thrust-measurement system is required to ensure that secondary load paths are negligible or can be accounted. Such load paths can result from external engine connections and interfaces, inlet seals, inlet pressure forces, engine-body pressure force differential, and nozzle drag, all of which combine to increase the measurement uncertainty. Proper secondary load-path bookkeeping has been a primary problem of past attempts at direct thrust measurement. As a result, the strain-gage technique has normally been used for simple engine arrangements such as pod installations under the wing. However, as this report shows, the technique can be properly applied to complex, buried-engine arrangements, provided care is used to ensure that nonnegligible secondary forces are understood and included in the analysis.

For installation environments subject to significant thermal cycling (such as with high-speed aircraft using augmented engines), the strain-gage measurement must be temperature-compensated, an important consideration for the calibration process. When a test program commences, depending on the program objectives and duration, in-flight tare readings against some reference (such as output from a simple engine performance specification model) may be prudent to highlight a need for sensor recalibration.

Published reports of successful applications of the strain gage-based direct thrust-measurement technique are not numerous. Two reported examples are a podmounted J85 (General Electric, Lynn, Massachusetts) engine installation tested on an F-106 airplane at speeds from Mach 0.6 to Mach 1.3 throughout the power range of the engine, ${ }^{3}$ and an F-14A TF30 (Pratt \& Whitney, West Palm Beach, Florida) engine application demonstrated at speeds from Mach 0.4 to Mach 1.6 at two power settings, including maximum augmentation. 4

The analysis discussed in this paper was performed using the NASA Advanced Control Technology for Integrated Vehicles (ACTIVE) F-15 aircraft. The ACTIVE test program ${ }^{5}$ is a joint effort between NASA Dryden Flight Research Center (Edwards, California); the United States Air Force (USAF) Materiel Command (Dayton, Ohio); Pratt \& Whitney, a division of United Technologies (West Palm Beach, Florida); and The Boeing Company (formerly McDonnell Douglas Aerospace) (St. Louis, Missouri). A major goal of the ACTIVE program is to demonstrate the benefits of a production-like thrust-vectoring system applied to the full flight envelope of a supersonic vehicle. ${ }^{6}$ These benefits include enhanced aircraft performance, maneuverability, and controllability.

Engine-mount strain gages were originally installed and calibrated for the primary purpose of monitoring net structural loads, but the extraction of usable thrust- and 
vector-force data was also deemed possible. The strain gage-based nozzle-vectoring force-measurement system has produced reasonably precise results and has become an element crucial to the success of the nozzle-vectoring program.

This paper presents the results of a strain gage-based direct thrust-measurement technique developed by NASA Dryden and successfully applied to the full flight envelope of the F-15 ACTIVE aircraft, which is powered by two F100-PW-229 (Pratt \& Whitney) turbofan engines. More than 5200 time cuts of data were processed for quasi-steady-state operating conditions to produce the results in this report, which represent a Mach range from 0.0 to 2.0 and altitudes from near sea level to higher than $45,000 \mathrm{ft}$. Measurement-based grossthrust values were obtained at maximum nonaugmented and maximum augmented power and are compared to the results from two analytically-based thrust calculation methods. The direct thrust-measurement technique and a description of the significant secondary force terms required to compute gross thrust are presented. In addition, the strain-gage installation and calibration processes for the axial-thrust measurement are described in detail, as are the important lessons learned. Use of trade names or names of manufacturers in this document does not constitute an official endorsement of such products or manufacturers, either expressed or implied, by the National Aeronautics and Space Administration.

\section{Aircraft Description}

The ACTIVE test aircraft (fig. 1) is a highly modified, preproduction, two-seat F-15B airplane on loan to NASA Dryden from the USAF. The aircraft was previously used for the USAF F-15 Short Takeoff and Landing/Maneuver Technology Demonstrator (S/MTD) program.

\section{Airframe}

Two large canards mounted on the upper inlet area, forward of the wing, comprise the dominant external feature of the vehicle differing from a standard F-15 airplane. To accommodate the off-axis force produced by the vectoring nozzles, certain engine-mount and supporting structure has been strengthened. The skin contour and structure in the aft fuselage area were also modified to accommodate the vectoring actuation system and to provide clearance for full nozzle-vectoring movement. The modified engine-mount structure is described in detail in the "Direct Thrust-Measurement System Description" section.

The aircraft is controlled using a quadruply redundant, digital fly-by-wire flight control system. All mechanical linkages between the control stick, rudder pedals, and control surfaces have been removed from the aircraft. The throttles digitally control the engines through the

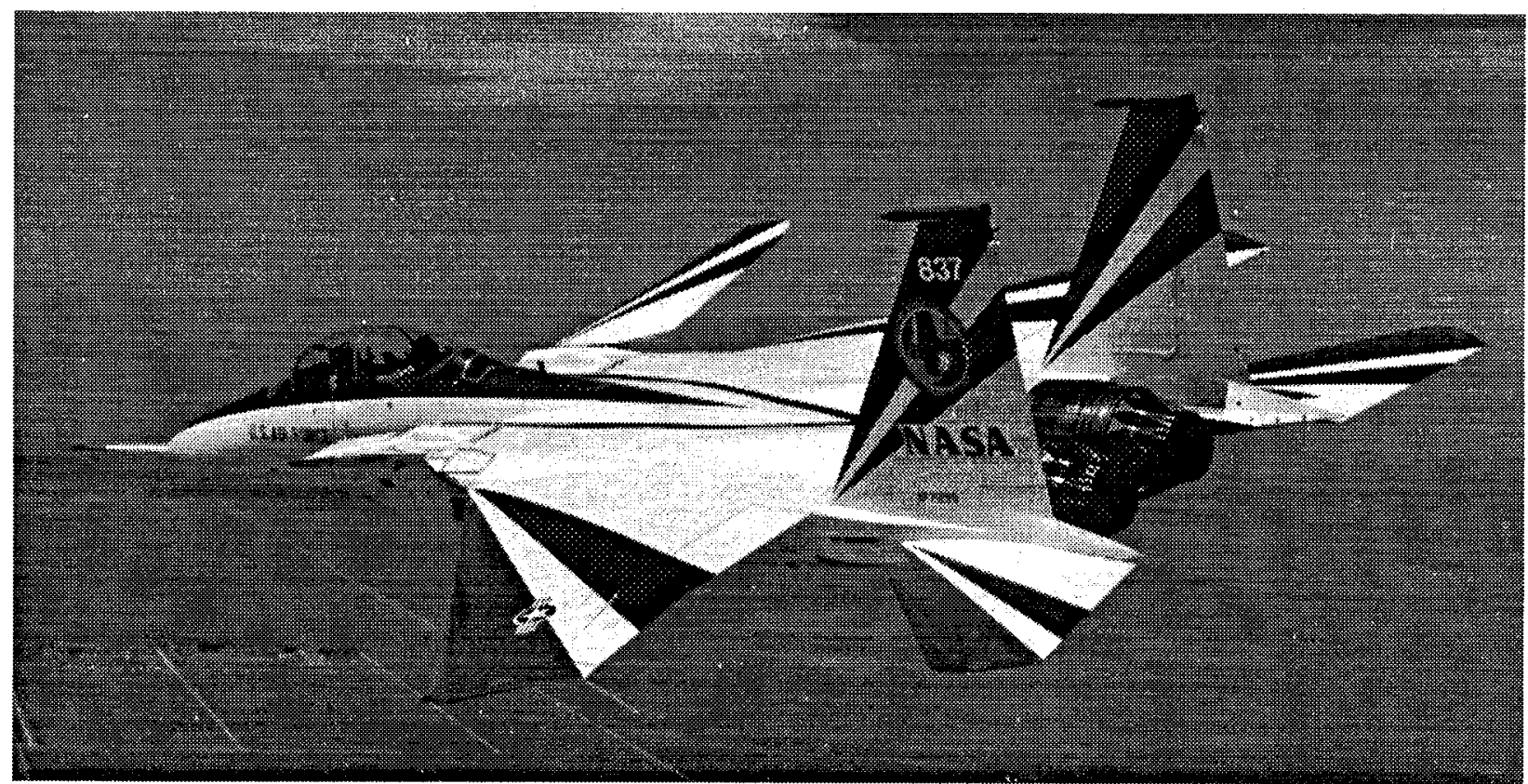

EC96 43485-3

Figure 1. The NASA F-15 ACTIVE test vehicle. 
flight controller, and no mechanical linkages exist between the throttles and the engines. Ten separate computers using 1553 multiplex data buses form the highly integrated flight and propulsion control system. These computers are used for digital flight, engine, nozzle, and inlet control; cockpit information management; pilot-vehicle interface; and auxiliary research computation capability.

The flight envelope of the F-15 ACTIVE vehicle is reduced compared to the production F-15 airplane. The composite material used to manufacture the canards limits the maximum Mach number to 2.0. The flight ceiling is an altitude of $50,000 \mathrm{ft}$ because the digital flight control system has not been cleared to higher altitudes.

\section{Propulsion System}

The ACTIVE propulsion system consists of two NASA-owned F100-PW-229 engines, each of which is equipped with a new-generation axisymmetric thrustvectoring nozzle. An engine-mounted improved digital electronic engine controller (IDEEC) and avionics bay-mounted nozzle controller provide closed-loop control of each respective component.

\section{F100-PW-229 Engine}

The F100-PW-229 engine is an augmented 29,000-lbf thrust-class motor that features a three-stage fan and ten-stage compressor, each driven by a two-stage turbine. An eleven-segment fuel delivery system is used within the augmentor. The full-authority IDEEC provides the pilot with unrestricted throttle movement throughout the flight envelope while maintaining engine operation within limits. A hydromechanical secondary engine control provides "get-home" capability if the IDEEC becomes unable to adequately control the engine. The addition of the vectoring system does not cause any loss of engine functionality, operational capability, or modification of fault accommodation.

Small modifications to the main body of the engine were required to support the addition of the vectoring nozzle. These modifications included strengthening the augmentor duct and front and rear fan ducts to accommodate the off-axial loads generated during nozzle vectoring.

\section{Nozzle-Vectoring System}

Each axisymmetric vectoring nozzle provides a maximum of $20^{\circ}$ of mechanical vector angle in any circumferential direction. Independent control of the nozzle exit area allows the nozzle exit-to-throat area ratio to be optimized for performance, unlike the standard F100 divergent nozzle section, which uses a mechanical linkage system that tracks throat area and pressure loads but is not capable of independent exit area modulation. Torsional freedom built into the divergent seal design permits the nozzle to maintain a tight gas-path seal even while vectored. The tight seal allows thrust coefficient performance nearly identical to a standard F100 nozzle while preventing vectoring flow instabilities. The majority of hardware forward of the throat is common to the standard nozzle. The convergent section maintains its mechanical and control independence from the divergent section despite the addition of the divergent section-vectoring system.

\section{Instrumentation System}

The aircraft has been extensively modified with a flight test instrumentation system for recording digital and analog sensor data. Approximately 3400 performance, flying qualities, structural loads, data bus, and propulsion parameters are recorded onboard the aircraft and are simultaneously downlinked to the NASA Dryden mission control center.

A description of the strain-gage thrust sensor arrangement, calibration, and data processing procedure is provided in the "Direct Thrust Measurement System Description" section. A discussion of the input parameters used in the analytical thrust calculation models as well as for converting the direct engine-mount force measurements into gross thrust can be found in the "In-Flight Thrust Analysis" section.

\section{Direct Thrust-Measurement System Description}

Figure 2 shows the basic engine-mount reactions. These longitudinal, vertical, and lateral reactions transfer the combined thrust, inertia, gyroscopic, and any nozzle airload forces into the fuselage structure. In



Figure 2. Left engine-mount reactions. 
the case of the ACTIVE program, pitch and yaw thrust vectoring superimpose additional forces on the mounts.

The mount arrangement is fairly typical for fighter aircraft designs with engines buried in the fuselage. The layout and hardware are designed such that the reactions are essentially statically determinate. For the front mount, a dog-bone hanger link with monoball bearings ensures that only vertical loads can be reacted and simuitaneously accommodates significant engine thermal expansion in the longitudinal direction.

Figure 3 shows the inboard main-mount and side-link arrangement. An adapter pin on each side of the engine is clamped in the main mounts, which are attached to a major bulkhead and support table. During installation, the engine is slid on rails into the bay, and the pin is inserted into the main bearing and then rolled into the mount. When seated, the pin is secured by the swing-down clamping jaw. To accommodate thermal expansion in the radial direction, the engine monoball bearings ride on the end of the pins that are coated with a high-temperature dry-film lubrication to minimize friction.

The pins react all of the thrust load and approximately 75 percent of the vertical inertia forces. Nozzle pitch vector generates additional vertical forces, and all of the moment produced by yaw vector is reacted through

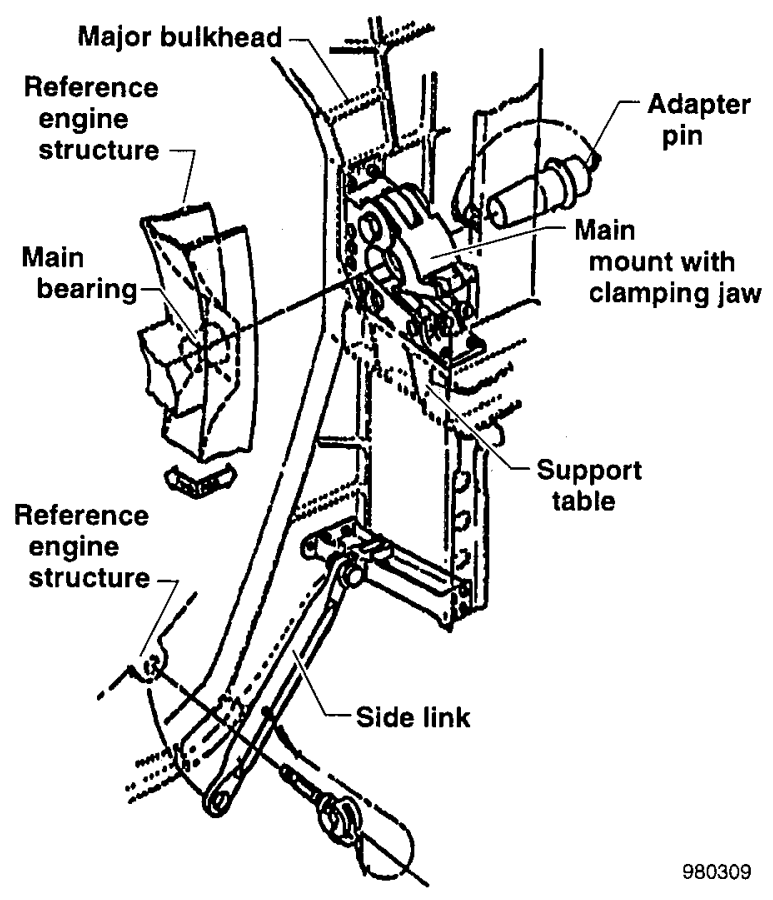

Figure 3. Inboard main-mount and side-link structure. differential thrust on the pins. The net force applied to the pin can thus be in any direction, depending on engine thrust, aircraft maneuvering kinematics, and vectoring. Ideally, all of the lateral inertia and yaw vector force is reacted by the side link attached to the lower part of the engine frame. This link keeps the engine approximately centered on the pins and prevents excessive sliding. In reality, some lateral load can be reacted by the pins through friction or binding.

For the F-15 ACTIVE program, certain engine-mount and supporting structure was strengthened to handle the additional vectoring forces. Measurement of the engine-mount forces thus originated as a structural loads objective. The most viable approach for monitoring the engine-mount loads was thought to be to directly intercept and measure the six load reactions identified in figure 2. Direct and reasonably accurate measurement of these components would satisfy safety-of-flight objectives during envelope expansion with the vectoring nozzles. At the same time, the realization was made that with high measurement accuracy and a good inertia and gyroscopic model, extracting thrust and vector forces to support research objectives, including correlation to conventional engine thrust models, would be possible. To extract thrust and vector forces, the assumption was made that some secondary load paths through engine system interfaces are not significant. Although desirable, instrumenting and directly measuring these secondary load paths is not generally viable. Potential sources for system interfaces that rob load from the engine mounts will be discussed in a later section.

As discussed in the introduction, few examples of previous successful engine-mount load measurement exist upon which to base or guide the ACTIVE program approach. Engine-mount load measurement has not been attempted in any past programs at NASA Dryden. During the preceding S/MTD program, ${ }^{7}$ the forward link was instrumented and 12 strain gages were installed on various parts of the engine-bay and main-mount table structure. The primary objective was safety-of-flight monitoring during pitch vectoring. Because of schedule and budget constraints, a ground calibration was not performed. Instead, calculated applied loads and flight-measured strains for nonvectoring maneuvers were used in an attempt to derive thrust and vertical load equations for the main mounts. Usable equations that could support safety-of-flight monitoring or research objectives were not able to be derived.

Even with an extensive ground calibration, this approach invites several problems. Foremost is that the engine-bay strain gages could respond not only to the 
main-mount loads, but also to other fuselage strains that have no relationship to engine-induced loads (including fuselage inertia loads and even horizontal and vertical stabilizer loads). Separating out these combined effects so that engine induced loads could be calculated would be nearly impossible. The engine-bay strain gages were also susceptible to thermal contamination. To generate the necessary thermal correction data, an engine-bay ground heating test could be conducted to simulate the thermal operating environment. For schedule, cost, and practical considerations, this type of test is generally not an option and was not performed for the S/MTD program.

The following sections discuss the strain-gage installation and calibration process, status, and lessons learned that have evolved in support of the ACTIVE program. The approach is founded on the direct and separate measurement of the thrust and vertical forces passing through the main-mount pins. As this paper is only concerned with main-mount thrust measurement and its conversion to gross thrust, details related to the link loads or vectoring forces will not be addressed.

\section{Strain-Gage Installation}

In order to install and calibrate strain gages on the main-mount pins, a fundamental starting requirement is to fix the angle at which the pin is clamped in the mount.
For this purpose, a V-shaped alignment pointer was installed in the mount end of each pin (fig. 4). This pointer mates with a matching plate secured to the back side of the mount, which forces the pin to the required angular orientation during engine installation. The pointer is a one-piece steel machining with a plug extension that is inserted into the hollow bore of the pin and secured with a machine-thread fastener adhesive. After a recent engine removal, inspection of the pins indicated that the bond on one of the pins was compromised. To preclude future problems, steel dowels were installed through the pointer face into the thick wall of the pins. This modification (not shown in the photo) provides a secure mechanical attachment that prevents any possible rotation of the pointer relative to the pin during engine installation or removal.

The line through the pointer apex is coincident with the thrust axis, and the vertical load axis is orthogonal. With these reference axes established, the strain-gage installation follows the layout defined in figure 5. The cola bottle-shaped pin is D6-AC high-strength steel, is very thick-walled, and tapers between the mount clamp zone and the small diameter where the engine bearing rides. Four-active-arm shear bridges are installed in the open area between these zones. Separate thrust and vertical load bridges are oriented to sense the shear load along their respective axes. A prime and spare bridge is

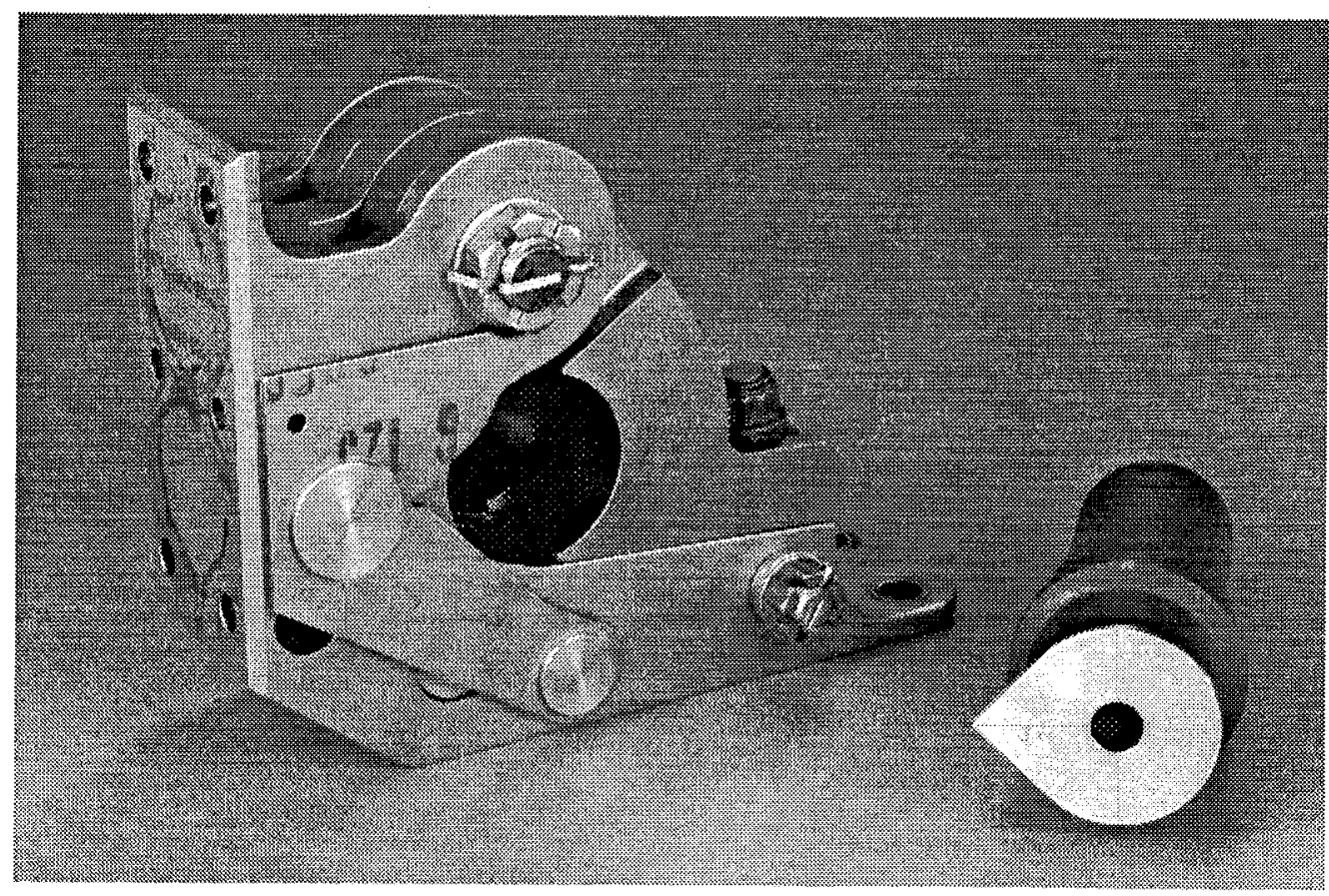

EC94 42762-3

Figure 4. Main mount, adapter pin, and alignment pointer. 
Bridge type: four-active-arm shear () in leg callout indicates back side
surface. Back side gages inverted to form $X$ pattern

Strain gages: Micro-Measurements WK-06-125TH-350

(Orthogonal two-element torque gage)

Thermocouple: RdF 20112

(type K chromel)

Terminal strips and interbridge wiring not shown

Section areas: 1.86 in $^{2}$ prime station 2.06 in $^{2}$ spare station

All dimensions in inches


Figure 5. Strain-gage and thermocouple instrumentation on outboard main-mount pin. 
provided for each axis, totalling four for each pin. The gages are Micro-Measurements (Measurements Group Inc., Raleigh, North Carolina) WK-06 series for increased toughness and temperature capability in the potentially harsh environment, temperature-matched for steel. The specific TH model gage used has a grid configuration with two orthogonal legs precisionaligned in a V shape. The other two legs are installed on the back side of the pin, but are rotated $180^{\circ}$ to form a superimposed $\mathrm{X}$ shape. This bridge configuration is considered the optimum for measuring shear and should be inherently insensitive to any lateral or torque loads on the pin.

To accommodate potential corrections for thermal errors in the bridge output, a type $\mathrm{K}$ thermocouple (RdF Corporation, Hudson, New Hampshire) is installed in the space between and close to the gages. Figure 6 shows a closeup photograph of the completed installation prior to application of a heavy protective coating of sealing compound. Interbridge wiring is routed to solder tabs located in the areas between the orthogonal axes, and from there, a single wire bundle with built-in strain relief is routed to a wall-mounted disconnect plug. With the 16 individual strain-gage legs, interbridge wiring, and thermocouple, the pin circumference is congested but manageable.
Prior to committing to this approach, potential problems and disadvantages with both the installation and obtaining a usable calibration were identified as discussed below:

- The usable space between the edge of the mount and the engine bearing is only approximately $1 \mathrm{in}$. The wear zones evident on the original pins from the previous program were surveyed to determine the maximum range of lateral bearing movement on the pin. The survey results dictated the safe area for strain-gage installation (figure 5 shows the worstcase bearing position and angle). New pins were obtained for the ACTIVE program so that the pins started with no wear.

- The close proximity of the gages to both the bearing and mount clamping zones generated concerns regarding localized loading and reaction effects that could produce a strain field that was not well-behaved. Such a strain field could lead to erratic, nonlinear response; hysteresis; and other undesirable effects. The strain gages are approximately centered between these zones, and an approximately 0.5 -in. gap exists from each strain gage to the edge of the nearest gage grid.

- The shear bridges had to be installed on a tapering cross section for this application, which a

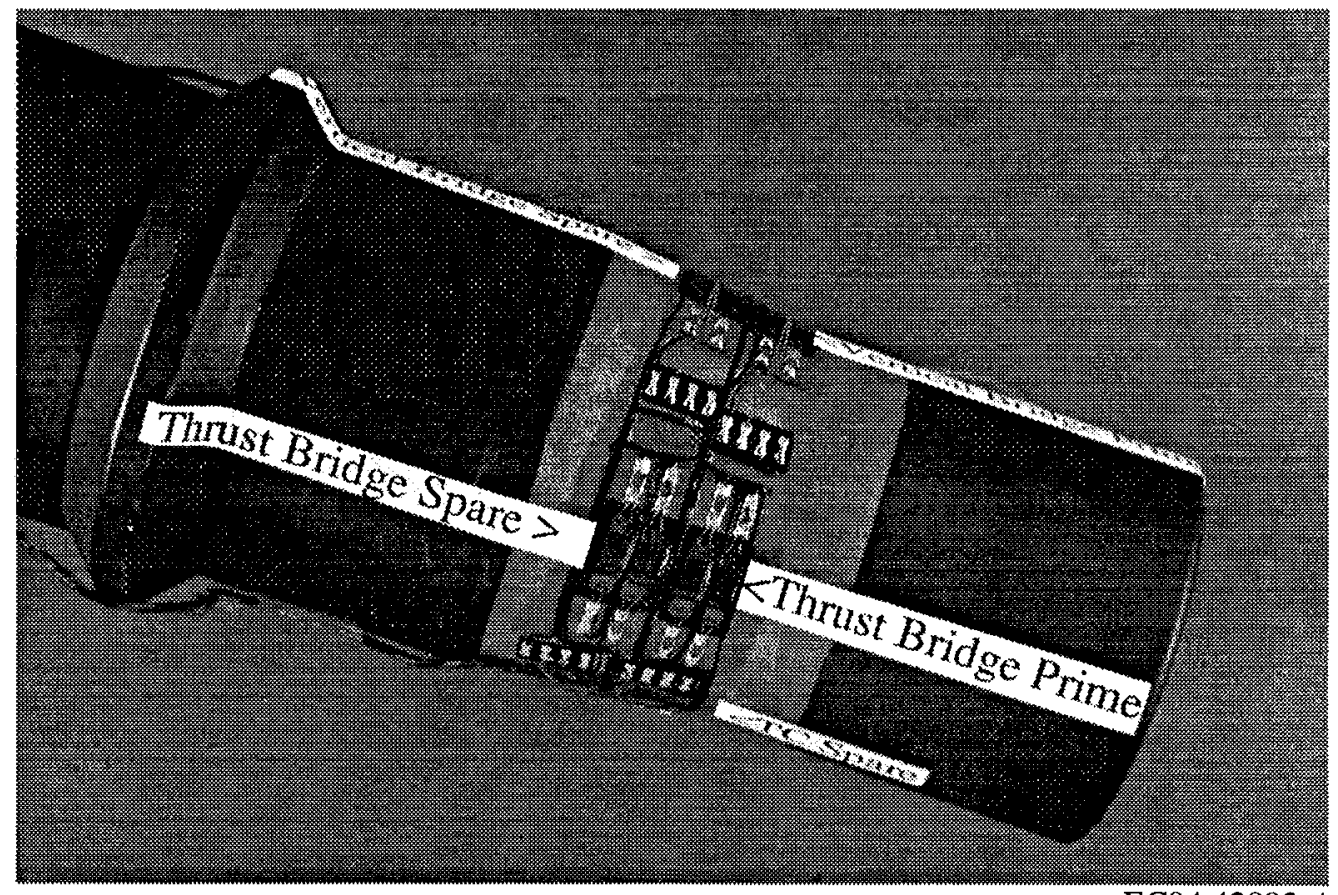

EC94 42893-4

Figure 6. Installed strain-gage instrumentation. 
sensitivity analysis indicated should not alone present any problems.

- To handle the design temperature of $350^{\circ} \mathrm{F}$ and be fatigue resistant, the pin has a very large margin relative to normal operating loads. This large margin produces fairly low shear bridge response, predicted to be approximately $10-12 \mathrm{mV}$ at load limit. For typical maximum thrust operating levels, the output would only be approximately 5-6 $\mathrm{mV}$. The low response could lead to noise problems and increase susceptibility to thermal contamination.

- Shear bridges can show some sensitivity to bending moment. The thermal expansion and lateral sliding of the engine produces a range of bearing positions that vary approximately $0.2 \mathrm{in}$. and are unpredictable. For the prime strain-gage station, this thermal expansion and lateral sliding produces a bending arm variation of approximately \pm 10 percent.

- One of the biggest concerns was the expectation for cross-axis loading effects. When a pure thrust load is applied, the vertical axis gages ideally produce little or no response. Conversely, the thrust-oriented gages ideally respond only to the component along the thrust axis. In actuality, the magnitude and behavior of these cross-axis effects would depend in part on the precision alignment and placement of the strain-gage installation. A good deal of care was taken in marking the axes and positioning the gages to minimize these effects.

- A level of concern existed regarding the potential for damage to the gages, wiring bundle, and pointer during engine installation, removal, and normal operation. The alignment pointer, in particular, requires some extra care and effort during engine installation, as the pointer must slide, without rolling, during the final seating in the mount. After 95 flights and several engine removals and installations, concerns in this area have diminished. The only problem to date has been that related to the pointer discussed earlier.

- Application of the calibration loads does require a custom fixture, as described in the next section.

The potential issues listed above were cumulatively imposing; however, the realization was made that if good pin calibrations could be obtained, then nonenginegenerated forces could not contaminate the strain-gage outputs. Some additional advantages inherent to this overall approach result from being able to remove the instrumented pins from the aircraft. One advantage is an off-aircraft calibration loading should be simpler, quicker, less costly, and less hazardous than an equivalent on-aircraft test. Another advantage is that with their relatively small size, the pins can be oven-tested to establish thermal corrections to the gage outputs, as discussed in a following section. Also, the pins could be installed in comparable mounts to conduct a test program on a different aircraft. These options do not exist if strain gages are installed on engine-bay or mount-supporting structure.

\section{Calibration Process}

The calibration process has evolved through four distinct steps summarized in table 1. The philosophy is

Table 1. Summary of calibration steps.

\begin{tabular}{|c|c|c|c|c|c|}
\hline Step & $\begin{array}{c}\text { Test } \\
\text { description }\end{array}$ & $\begin{array}{c}\text { Primary } \\
\text { objectives }\end{array}$ & $\begin{array}{c}\text { Key } \\
\text { elements }\end{array}$ & $\begin{array}{c}\text { Test } \\
\text { complexity }\end{array}$ & $\begin{array}{c}\text { Test } \\
\text { time span }\end{array}$ \\
\hline 1 & $\begin{array}{l}\text { Off-aircraft } \\
\text { fixture loading }\end{array}$ & $\begin{array}{l}\text { Derive strain-to-load } \\
\text { calibration equations }\end{array}$ & $\begin{array}{l}\text { Shear loading fixture } \\
\text { Instrumented pins in } \\
\text { main mounts }\end{array}$ & Simple & $\begin{array}{l}1 \text { day for } \\
\text { each pin }\end{array}$ \\
\hline 2 & $\begin{array}{l}\text { On-aircraft } \\
\text { laboratory test } \\
\text { "Cold loads" }\end{array}$ & $\begin{array}{l}\text { Verify accuracy of } \\
\text { strain-gage equations } \\
\text { Establish baseline } \\
\text { engine deflections }\end{array}$ & $\begin{array}{l}\text { Dummy engines with } \\
\text { calibrated pins } \\
\text { Simulate full thrust } \\
\text { and vectoring }\end{array}$ & $\begin{array}{l}\text { Moderate } \\
\text { to complex }\end{array}$ & $\begin{array}{c}\sim 3 \text { weeks } \\
\text { (10 test days) }\end{array}$ \\
\hline 3 & $\begin{array}{l}\text { Off-aircraft } \\
\text { heating test }\end{array}$ & $\begin{array}{l}\text { Derive strain-gage } \\
\text { thermal corrections }\end{array}$ & $\begin{array}{l}\text { Instrumented pins in } \\
\text { laboratory oven }\end{array}$ & Simple & 2 days \\
\hline 4 & $\begin{array}{l}\text { On-aircraft } \\
\text { combined } \\
\text { systems test } \\
\text { "Hot loads" }\end{array}$ & $\begin{array}{l}\text { Validate operation of } \\
\text { all integrated systems } \\
\text { Correlate thrust models } \\
\text { to measurements }\end{array}$ & $\begin{array}{l}\text { Aircraft restrained on } \\
\text { thrust stand } \\
\text { Full thrust and } \\
\text { vectoring }\end{array}$ & $\begin{array}{l}\text { Moderate } \\
\text { to complex }\end{array}$ & $\begin{array}{c}\sim 2 \text { weeks } \\
\text { (5 test days) }\end{array}$ \\
\hline
\end{tabular}


common to many flight tests: start with a relatively simple basic step, and with each new step, add complexity, understand and control errors or problems, and incorporate lessons learned from preceding steps.

\section{Off-Aircraft Fixture Loading}

The first step established the basic calibration equations to convert the measured strain-gage outputs (measured in $\mathrm{mV}$ ) to the desired force quantities (measured in lbf). For this purpose, a shear-loading fixture (fig. 7) was constructed. A main mount from the airplane was used to hold the pins, and loads were applied through a hydraulic jack, a load cell, and "lollypop" hardware containing a bearing obtained from the engine manufacturer. All of this hardware was mounted on a large I beam. The calibration process required loading the pin at various angles to simulate the combinations of thrust and vertical load expected in flight. To simplify the fixture setup, the following procedure was devised: the pointer mating plate was removed, and instead, a custom protractor template made from a viewgraph transparency was taped to the back side of the mount face. So, rather than rotating the whole jack structure to apply loads at varying angles, the pin or pointer was simply rotated to the desired angle and reclamped in the mount. The mount itself was always loaded in the thrust direction.

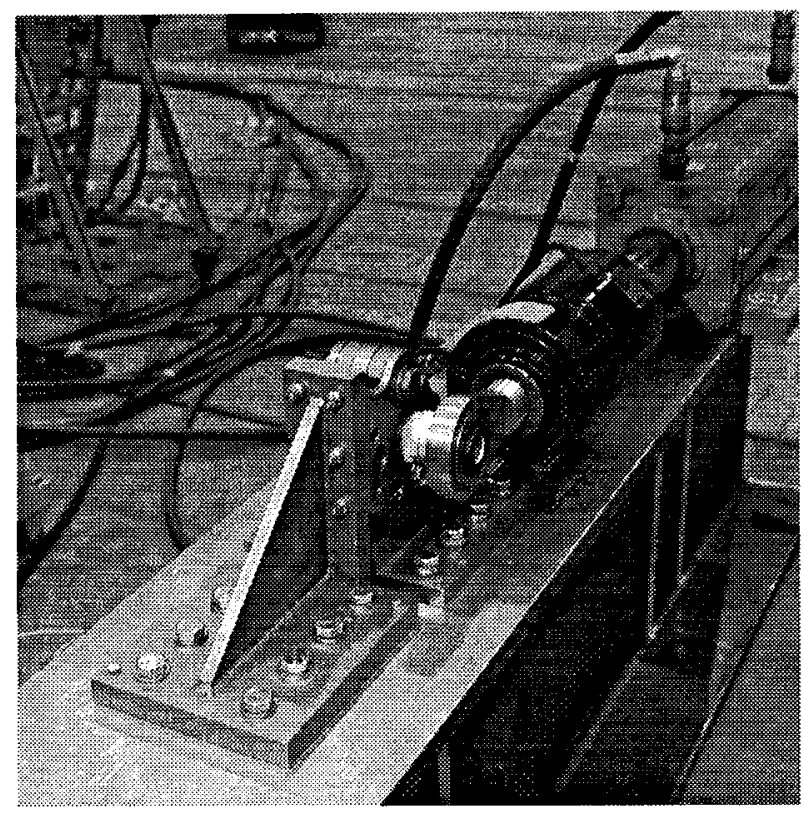

EC94 42896-5

Figure 7. Pin calibration shear-loading fixture.

Each pin was loaded at six different angles that covered the normal operating portions of the main-mount strength envelope. These loading conditions (fig. 8) are superimposed on the strength envelope

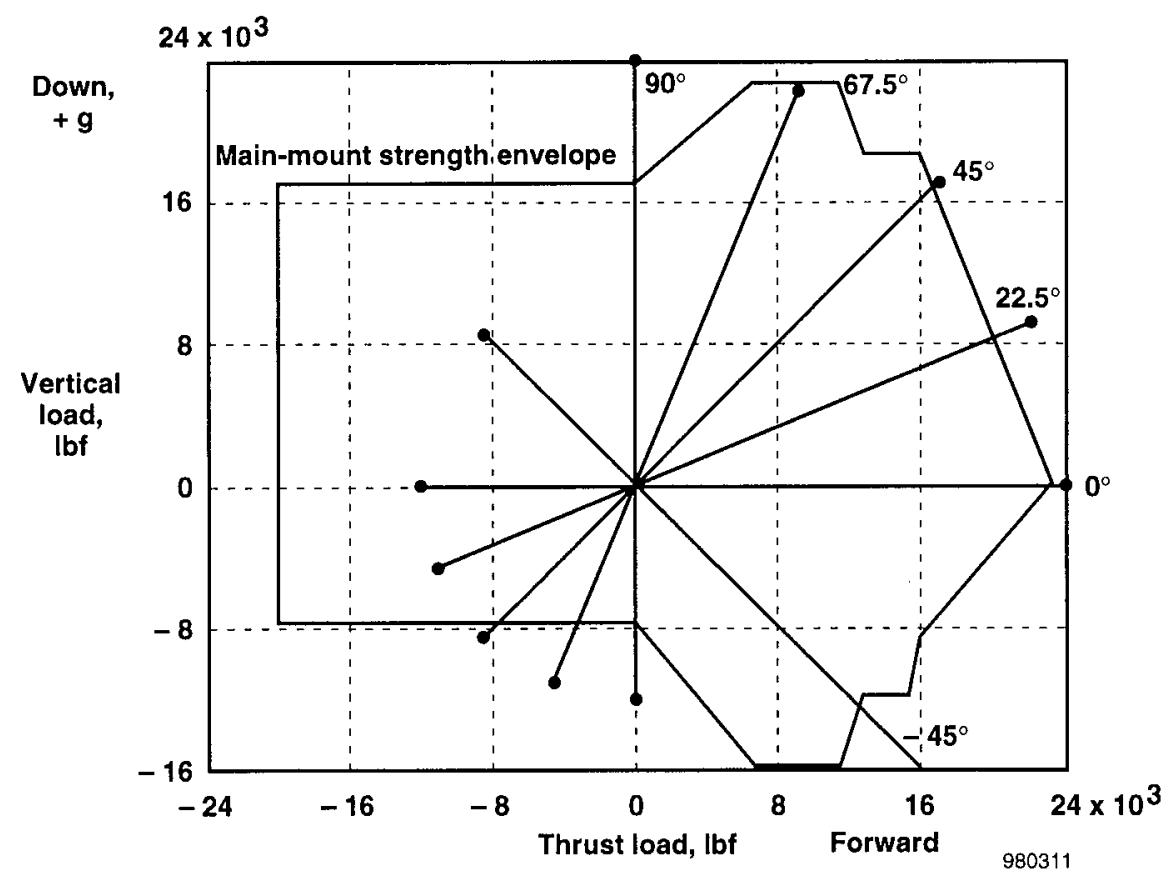

Figure 8. Pin calibration loading conditions. 
defined in terms of vertical load limit as a function of thrust load. Positive vertical load is a down load on the mount, corresponding to a positive aircraft load factor. Initial loadings ranged from $27,000 \mathrm{lbf}$ forward to $-20,000 \mathrm{lbf}$ aft (approximately 115 percent of the flight operating limits) using a slow ramping profile. Because the gage outputs were fairly linear, the profile was reduced for most runs to the range from 24,000 to $-12,000 \mathrm{lbf}$ shown in the figure. The first quadrant, representing forward thrust and positive $g$, is wellcovered, as this quadrant is the normal operating region where calibration accuracy is most important. Negative $g$ or aft thrust conditions were given less emphasis. At each angle, the pin was loaded at the most inboard and outboard bearing positions to assess the bending and localized loading effects discussed previously. Figure 5 shows these positions in the lower rear view.

The calibration data for the 8 bridges (prime and spare for thrust and vertical for each of the two pins) were evaluated for each of the 12 loading cases ( 6 angles for 2 lateral positions each). Figure 9 shows an example of the bridge output for the prime thrust bridge on the outboard pin (measured in $\mathrm{mV}$ ) plotted as a function of applied load for all 12 loading cases. This example is typical of all the prime bridges. Looking first at the response for the primary axis loading $\left(0^{\circ}\right.$, thrust axis with no vertical component), the output is quite linear over the positive load range. The difference between the two lateral loading positions (open and solid symbols) is minor, less than 1 percent in slope. A least-squares slope, based on the positive data, is extended through the negative region to show that the response is slightly greater for aft thrust- axis loading.

Bridge output for loading in the vertical axis at $90^{\circ}$ would ideally be $0 \mathrm{mV}$. The measured response is approximately 3 percent of that for the thrust axis. For loading angles representing various combinations of thrust and vertical load, the response is also greater than would be expected from multiplying the $0^{\circ}$ slope by the cosine of the angle, as indicated by the lines labeled on the right border. For example, data for the $45^{\circ}$ and $68^{\circ}$ loading angles are 6 and 12 percent greater, respectively, than would be expected. Repeat loading cycles showed the data to be very repeatable and well-behaved, but these cross-axis effects indicate that a single-bridge thrust equation with high accuracy over any loading angle is not feasible.

Data from all 12 loading conditions were processed through a regression analysis to evaluate two-bridge equations that combine a thrust bridge with a vertical bridge. Figure 10 shows the resulting equation accuracy for the prime bridges on the outboard pin. The equation, listed at the top of the figure, uses the vertical bridge output with a relatively small coefficient to correct for the cross-axis effects. To obtain the best accuracy in the

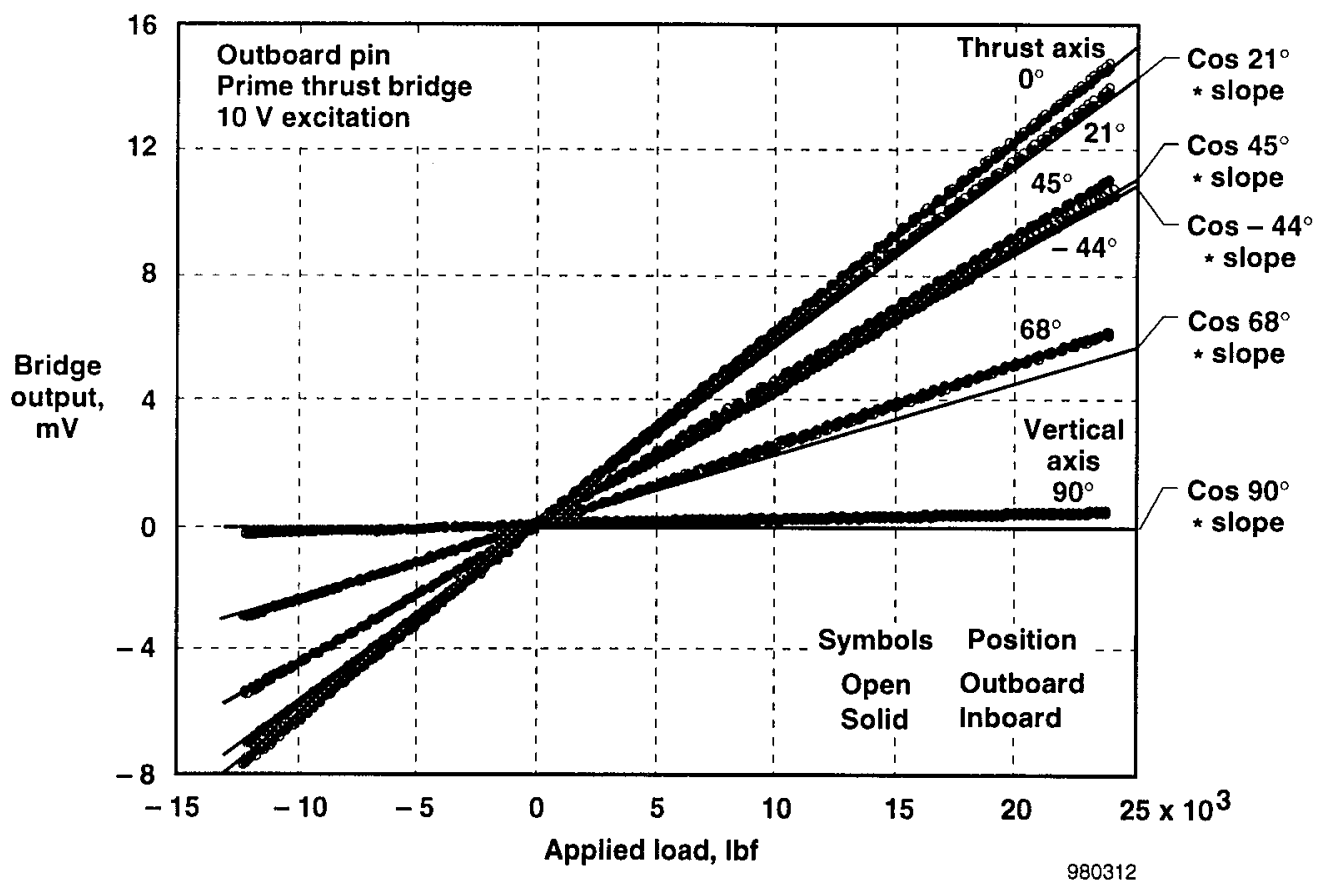

Figure 9. Typical bridge output for shear fixture loadings. 


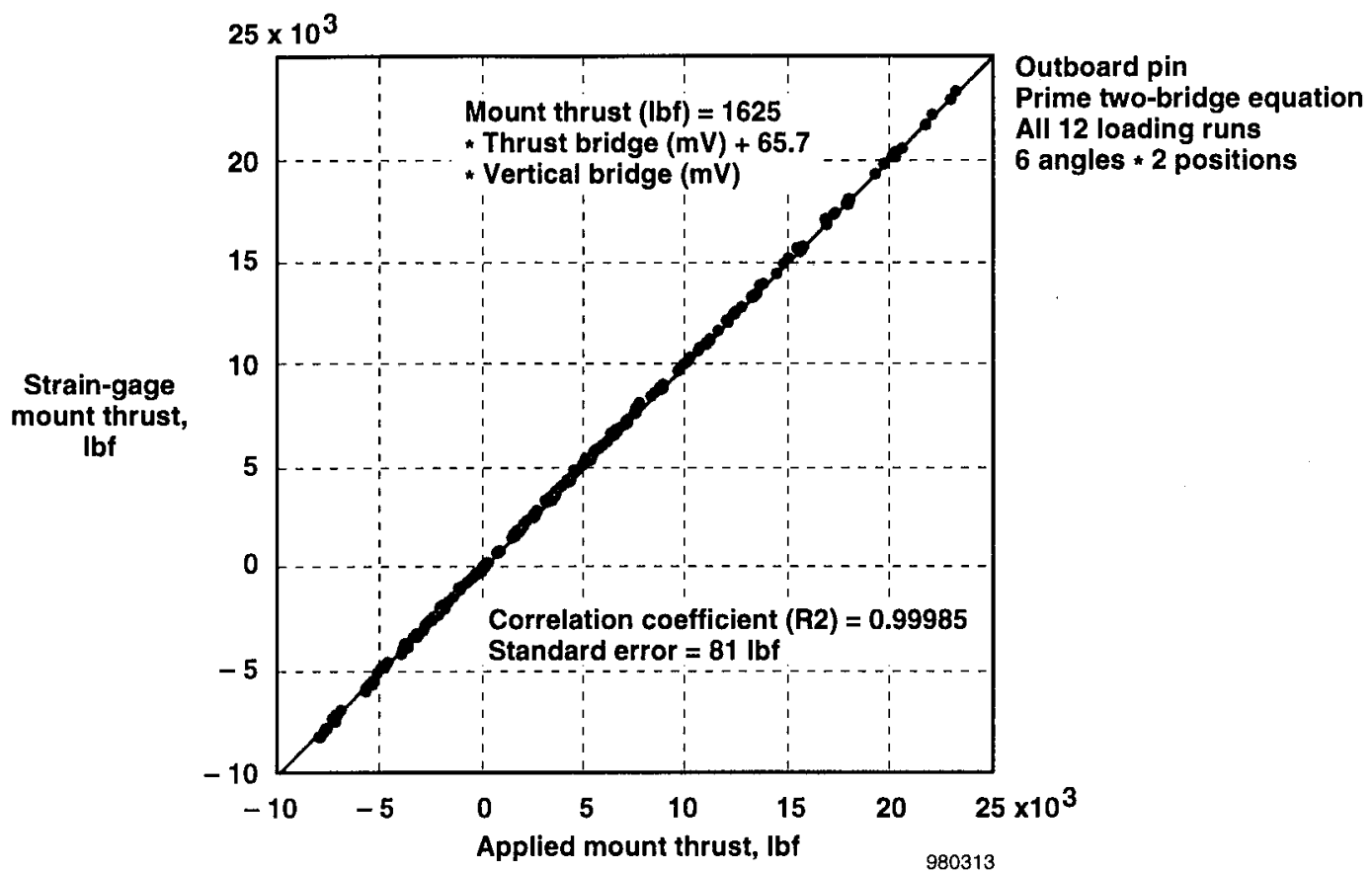

Figure 10. Thrust equation accuracy for shear fixture loadings.

positive thrust direction, aft thrust data were excluded from the regression analysis; then the increased error in this region was accepted. The regression equation does a remarkable job for any loading angle or lateral position. The correlation coefficient and standard error for this fit are shown on the figure. The 3- $\sigma$ error divided by the maximum load is 1 percent.

Figure 11 shows the discrete error for each data point plotted. The final equation coefficients were manually tuned to minimize and balance the errors for the positive thrust and positive $g$ loading conditions. This tuning produced a maximum error band of $\pm 200 \mathrm{lbf}$ for these conditions. For the low-angle loadings most pertinent to this paper, figure 11 (a) shows that the maximum hysteresis spread is approximately $\pm 50 \mathrm{lbf}$, and the largest difference between the lateral loading positions is $200 \mathrm{lbf}$. Thrust errors for the more acute angles, representing significant $g$ loadings (fig. 11(b)), are also minimal except for the less important $-44^{\circ}$ condition. Prime equation accuracy for the inboard pin thrust was comparable to that discussed here. Accuracies for the prime vertical equations or those using the spare bridges were not quite as good, with 3- $\sigma$ errors varying from 2 to 4 percent. The overall assessment, however, is that the calibration equations resulted in as near optimum a set of shear sensors as could be hoped for, especially considering all the potential issues discussed earlier.
One negative aspect that was not anticipated, however, was uncovered in the shear fixture loadings. The clamping jaw exhibited what could be considered excessive flexibility. This flexibility allowed the pin to yaw, causing substantial gapping between the pin and the bore face. The amount of gapping was dependent on the magnitude and direction of the applied load. A deflection transducer was added to the test setup to measure the fore and aft yawing of the pin because this addition produces an additional source for engine movement relative to the bay. At maximum thrust, the engine is expected to move forward $0.05 \mathrm{in}$. because of the pin-and-mount assembly flexibility in addition to airframe flexibility and thermal expansion effects.

This gapping also generated additional concern that the cross-axis effects mentioned above would not be properly simulated because the pin was rotated instead of the jack. The clamping flexibility, and thus the gapping characteristics, could be different for each mount and loading angle. Cross-axis bridge output was 2-4 percent of the primary axis output for the prime bridges, but was 10-15 percent for the spares, which are closer to the mount, indicating that the clamping and gapping characteristics can affect the bridge response. The simplification in the test setup thus produced some compromise in the fidelity of the simulated loads that could influence the validity of the excellent calibration 


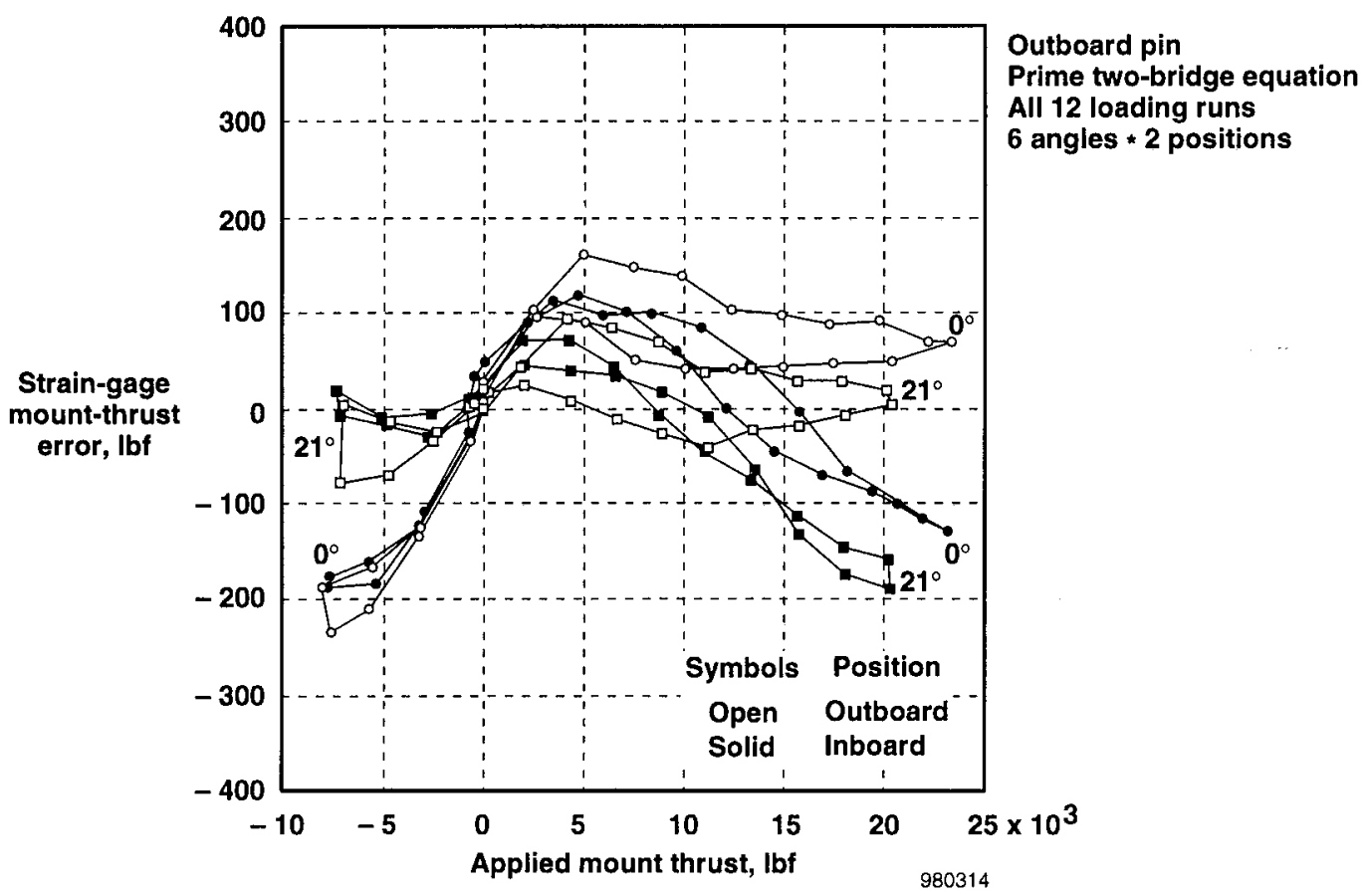

(a) Low angle loadings.

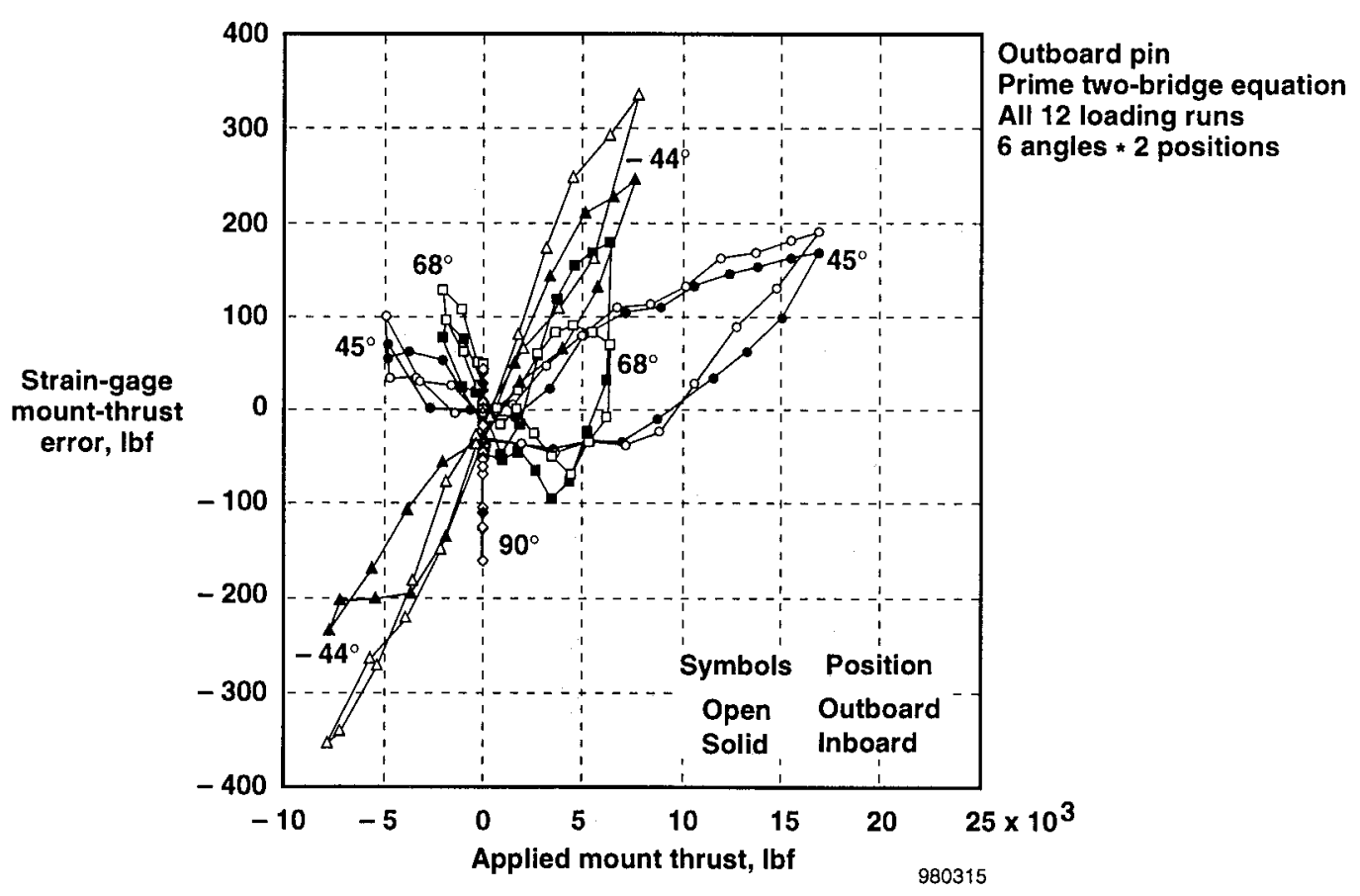

(b) High angle loadings.

Figure 11. Thrust equation error for shear fixture loadings. 
equations just discussed. The ground test schedule did not allow consideration for redesigning the fixture setup and repeating the loadings. Instead, the on-aircraft laboratory test, described next, would be used to check the calibration validity.

\section{On-Aircraft Laboratory Test ("Cold Loads")}

In early planning of the overall ground test program, the necessity and importance of conducting an on-aircraft laboratory test was debated, especially in light of the effort and time required and that a combined systems test with engines installed and operating (the "hot loads" test) was already planned. In reality, the on-aircraft laboratory test without engines installed (the "cold loads" test) supported the multiple objectives listed below:

1. Validate the aircraft restraint system to be used in the "hot loads" test.

2. Satisfy proof test requirements for the strengthened aircraft structure.

3. Establish baseline engine deflections relative to the bay.

4. Verify side-link and main-mount friction characteristics.

5. Establish the accuracy of baseline strain-gage equations.
In lieu of "cold loads" testing, objectives 1, 2, and 3 could be accomplished during "hot loads" testing. The "hot loads" test could be used to validate the strain gage-derived thrust equation, but could not address elevated $g$ maneuvering or vector-force calculations. With the concerns expressed in the previous section regarding the main-mount flexibility, the desirability of conducting the "cold loads" test to support objectives 3 and 5 was considerably elevated.

Figure 12 shows a rear view of the test setup in the NASA Dryden Flight Loads Laboratory. Two "sewer-pipe" engine fixtures were installed using the calibrated pins and links. These dummy, or "cold," engines were available from early F-15 structural testing and modified to take vector loadings. The engines realistically simulated the engine mount points but did not simulate any of the engine system interfaces. Ballast was added to match the dead weight on the pins for the actual engines. The thrust loading jacks can be seen extending horizontally to the engine aft lug plates. Additional jacks for pitch and yaw vector loadings also attach to the same lug plate. Just forward of the main mounts, a jack to apply simulated vertical $g$ loadings was attached at the engine center of gravity by cutting a small hole in the bay door.

The airplane was restrained using the same hardware developed for the "hot loads" test. This hardware

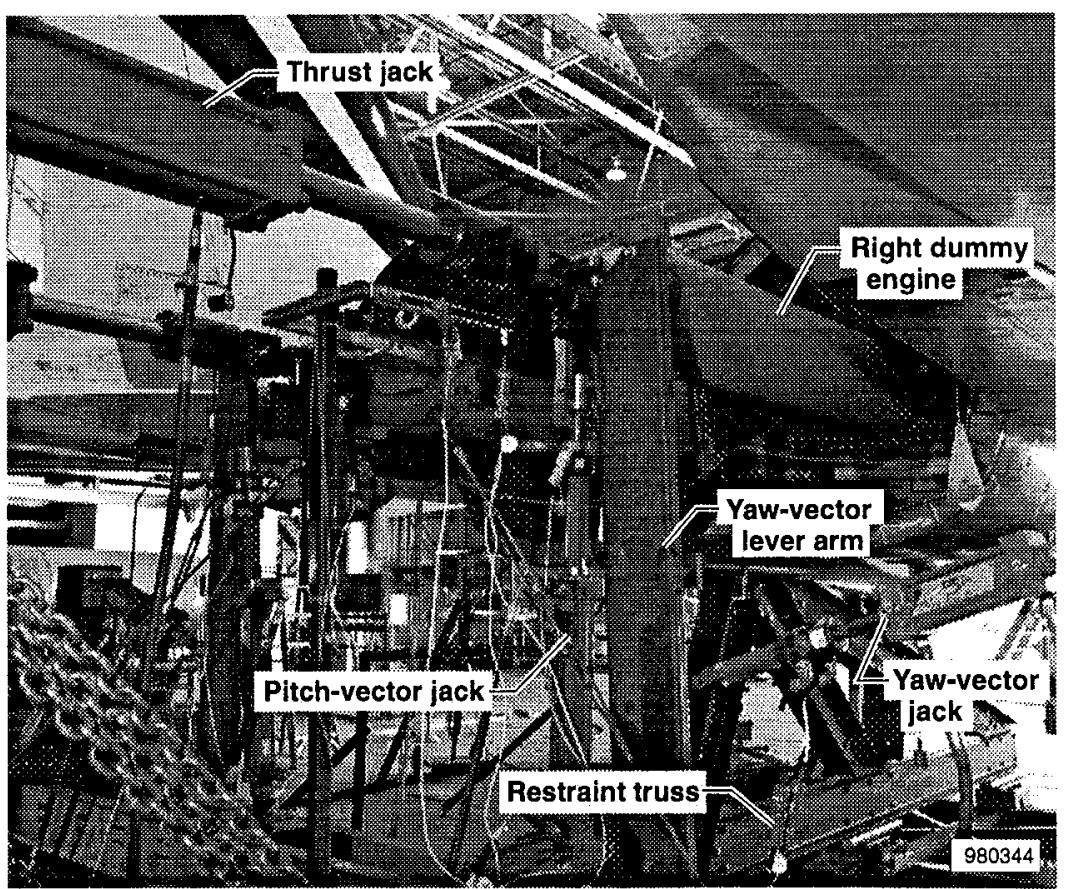

Figure 12. "Cold loads" test setup in the flight loads laboratory. 
consisted of spare main landing gear, bottomed out and secured in massive cradles; and the attachment of a large truss structure to the arresting hook trunnions. Test measurements consisted of 16 mount strain gages, 7 hydraulic jack loads, and 14 displacement transducers to establish engine and aircraft deformations. Note that, because of the vector-force requirements, the overall test setup was far more complex than would be required for testing just thrust and $g$ loadings. For a typical nonvectoring fighter configuration with a much simplified restraint and loading system, the test could have been conducted within a one-week span. The "cold loads" test required approximately three weeks dedicated aircraft time, including setup, testing, and teardown.

The test was considered very successful and produced valuable data in support of all five objectives. Maximum loadings simulated were as follows:

- Mount thrust of 20,000 lbf (for each engine)

- Vertical load factor equal to $5 \mathrm{~g}$

- Pitch and yaw vector force greater than 110 percent of design limit

- Combinations of the above including simulation of pitch-yaw vectoring at maximum thrust and elevated $g$
Significant results pertinent to this paper related to "cold loads" test objectives 3 and 5 follow below. Engine displacements relative to the bay were measured in all three axes at the inlet seal on the left engine, along with lateral movement at the main-mount pins. At maximum thrust, the longitudinal displacement was approximately 0.1 in. For the unrestrained airframe in flight, some additional displacement combined with thermal expansion is likely. The test matrix provided extensive data for evaluating the baseline strain-gage equations derived from the fixture loadings. Because the buildup test matrix progressed from individual jack loadings to many realistic combination loadings, assessing the equation errors for each loading scenario was possible.

Figure 13 shows the accuracy of the combined mount-thrust calculation for two loading cycles. The correlation is excellent to a maximum level of $5000 \mathrm{lbf}$, but then tracks 2-3 percent high from that point to maximum load. The hysteresis band is approximately $\pm 100 \mathrm{lbf}$. Examination of the individual pin thrust data indicates most of the error is caused by the inboard pin, with the outboard pin showing nearly zero error over the entire thrust range. The overall correlation is still considered very good for a pure thrust loading, but potential for improvement does exist.

Large errors occur for the off-axis loadings, particularly for vertical $g$ loading, as shown in figure 14 .



Figure 13. Thrust accuracy during "cold loads" test. 




Figure 14. Thrust error caused by vertical $g$ loading.

The 20,000-lbf vertical load endpoint equates to an equivalent $5-g$ condition. For the two cases where thrust was applied first, the error starts high, as shown by figure 13. As the vertical loading is applied, the error reverses with a gradient of approximately $-300 \mathrm{lbf} / \mathrm{g}$. The total change of $-1200 \mathrm{lbf}$ from 1 to $5 \mathrm{~g}$ would represent a significant and artificial thrust loss during turning performance or drag polar work. Smaller but still significant errors in thrust occurred for pitch vectoring. Until additional regression analysis is performed using the "cold loads" data, the current mount-thrust calculation is considered inadequate for useful research at elevated $g$ or during vectoring. Mostly for these reasons, the thrust comparisons in this paper exclude aggressive maneuvering and vectoring.

Flight data for cases where the mount loads are not significantly changing in both axes simultaneously are still considered quite valid. But the "cold loads" test provided important evidence that improvement in the primary force calculations and minimization of the cross-axis effects is desired. Most of the errors identified during the "cold loads" test are attributed to the pin and mount gapping previously discussed. The flight results in this paper use the baseline equations from the shear fixture calibrations with no corrections from the "cold loads" test.

\section{Off-Aircraft Heating Test}

With strain gages matched to the material, a four-active-arm bridge is normally expected to be selftemperature compensating. Because of the relatively low output on the pins and the encouraging load calibration results, the decision was made to run apparent-strain tests to determine if thermal contamination errors would be worth correcting. The instrumented pins and links were placed in a thermal testing oven, and the bridge output was measured as the temperature was slowly ramped over the operating range. Because of their relative bulk, the pin thermocouples showed large lags compared to the oven temperature. Worst-case bridge outputs varied greatly from bridge to bridge, from as low as $0.02 \mathrm{mV}$ to as much as $0.65 \mathrm{mV}$. These thermal errors are not large in $\mathrm{mV}$ terms, but because of the relatively low output caused by mechanical load, these errors can represent noteworthy errors in the load calculation.

Figure 15 shows the equivalent load errors for the prime thrust bridges and the load errors summation that equates to the mount-thrust calculation. The actual $\mathrm{mV}$ output error is shown in the right margin. Normal in-flight operating temperatures at high power settings are 200 to $250{ }^{\circ} \mathrm{F}$, based upon flight data. The temperature environment is thus considered warm, not 


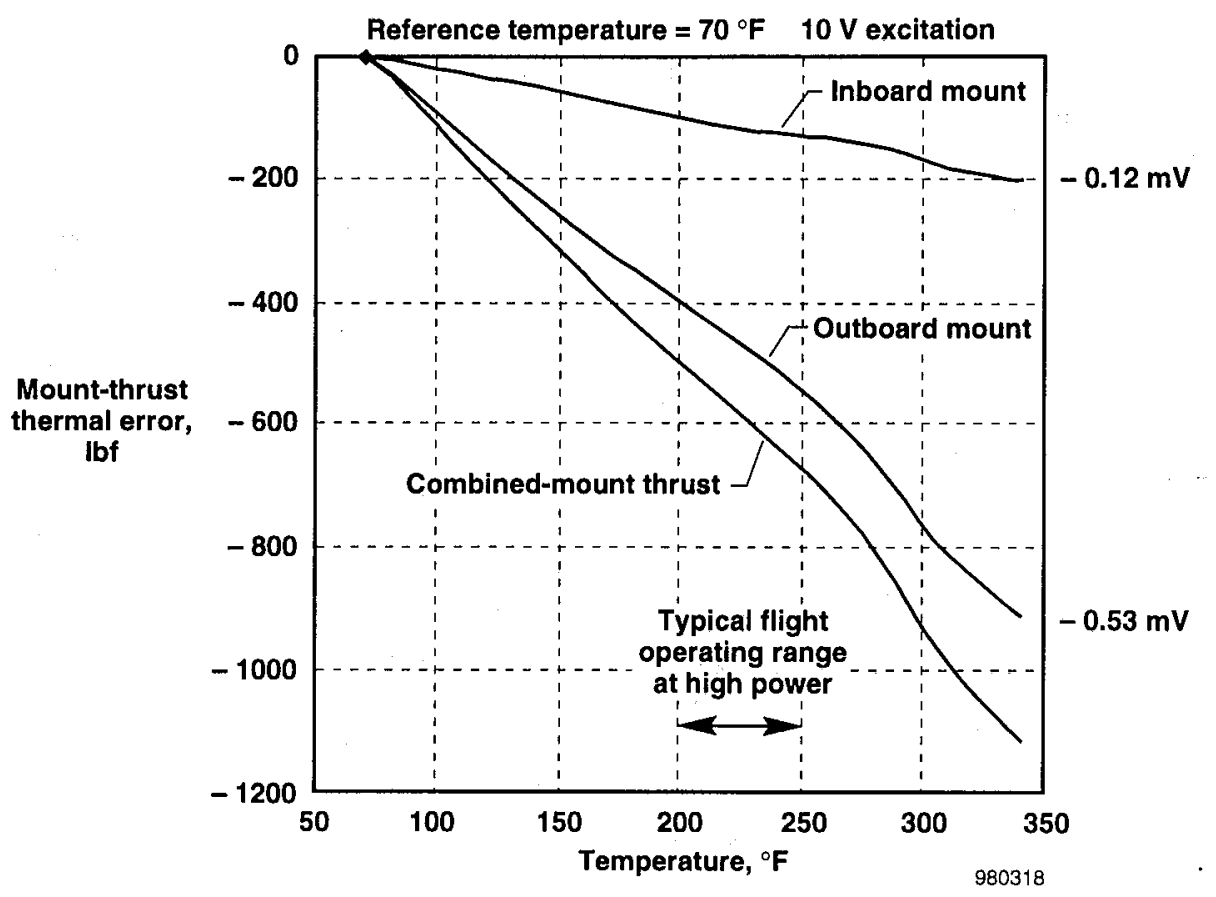

Figure 15. Thrust error from heating test.

hot, but the combined error in the mount-thrust equation would be approximately $700 \mathrm{lbf}$. At typical maximum augmented (maximum) power conditions, this value represents a mount-thrust error of approximately -3 percent, increasing to -6 percent at maximum nonaugmented (military) power levels. The apparent-strain corrections for some bridges are thus considered important, not only for research quality data, but also for safety-of-flight monitoring.

Many of the bridge outputs showed minor nonlinearity with temperature, but simple linear fits were derived for each bridge and were thought to be adequate. Output correction terms (measured in $\mathrm{mV}$ ) took the form of a constant multiplied by the difference in temperature from a reference state, which simplified the real-time and postflight data processing. Some effort has been made to validate the individual thermal corrections using data from the "hot loads" test, but the results are not fully conclusive.

\section{Aircraft Combined Systems Test ("Hot Loads")}

The combined systems ground test was the definitive clearance check performed prior to committing the aircraft to flight. Major objectives included operational validation of all integrated systems, both hardware and software. In particular, validation of the onboard thrust model and the vector-force limiting logic was key. The aircraft, restrained on the thrust stand facility at Edwards Air Force Base (California), was capable of demonstrating full vectoring with both engines at maximum power. Relative to "cold loads," this testing added the elements of thermal effects and engine system interfaces, but did not have inertial $g$ forces adding to the measured engine-mount data. Prior to installing the engines, a survey of the engine bay was conducted to assess the most likely sources for secondary load paths. The highest potential candidates were identified as the following:

- Engine-face inlet seal: Under worst-case high power conditions, combined thermal growth and deformations could have fully compressed the rubber seal, allowing some thrust transfer through the supporting structure.

- Airframe-to-nozzle fairings: The fairings are cinched down onto a nozzle rub strip. If the cinch straps were overly tight, a potential for reacting thrust existed.

- Engine-bleed air duct: The design has built-in flex elbows that accommodate engine pitch and yaw movements. How the design would handle forward engine movement caused by the pin and mount flexibility was not obvious from visual inspection. Forward engine movement could have affected the outboard mount-thrust measurement. 
None of the above issues alone created major concern, but their combined effect could have some potential for robbing thrust from the main mounts. All other system connections (hydraulic, fuel, and electrical) were not a concern because of built-in flexibility.

Correlating the strain gage-derived thrust to the measured readings obtained using the thrust stand and output from two analytical thrust models (discussed in the following section) had very encouraging results. Figure 16 shows this comparison, which plots the percent error, relative to the thrust stand, as a function of throttle setting. Data are shown for the baseline equations and a modified result using corrections from the "cold loads" test. Both sets of data use the baseline thermal corrections. The strain-gage data incorporated standard tare corrections, which forced the thrust calculation to read $0 \mathrm{lbf}$ prior to engine start. Relative to a \pm 2 -percent error band (a targeted goal), the postflight model is outstanding over the entire power range. The onboard model and the modified strain-gage results skirt the \pm 2 -percent band, except at idle power where the thrust is extremely low. To compare well, the thermal corrections had to be reasonable. The secondary load paths caused by the system interfaces appeared to be minimal, which verifies initial assumptions.

\section{Flight Data Extraction of Mount Thrust}

The mount strain gages respond to the net structural loads, which represent a summation of the applied forces: thrust, vector, inertia, and gyroscopic loads, and any external airloads. If these latter forces can be accurately computed and subtracted from the measurements, the thrust, pitch, and yaw vector forces can be determined from the statically determinate reaction equations. Fortunately for the mount-thrust calculation, the only inertia force is that caused by longitudinal acceleration. This term can be a significant but simple correction for large accelerations. A fair amount of effort has gone into careful engine weight-and-balance checks to establish confidence in the inertia properties. The longitudinal inertial load is the only force term accounted for in the baseline data processing before the mount thrust is converted to gross thrust (described in the next section).

The baseline strain-gage flight data processing is straightforward and consists of the following steps:

1. Correct the raw bridge outputs for variation in excitation voltage.

2. Correct bridge outputs for thermal error.

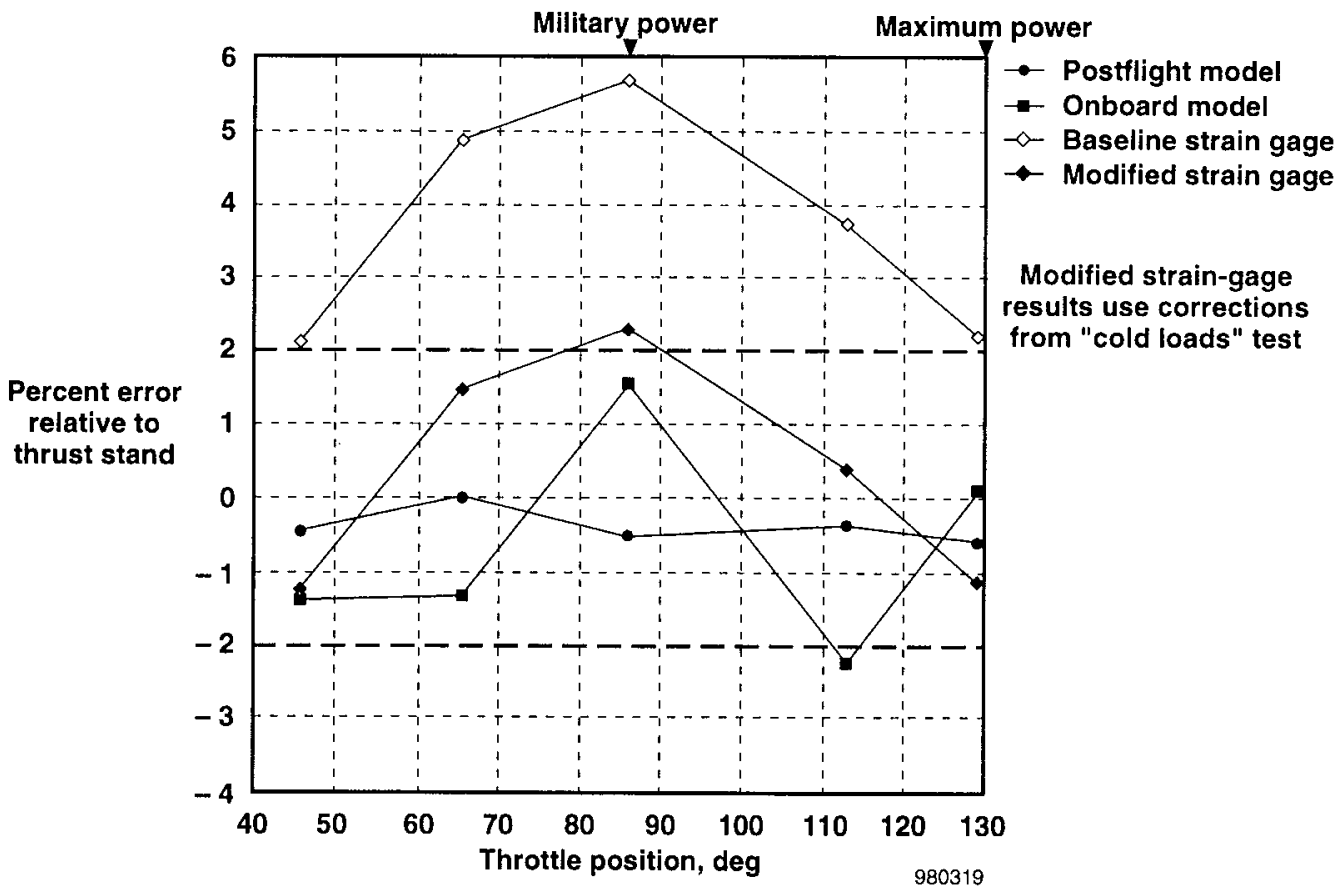

Figure 16. Thrust accuracy from "hot loads" test. 
3. Process corrected outputs through the load calibration equations.

4. Subtract inertia forces from the pin thrust loads.

5. Sum the outboard and inboard pin loads.

6. Apply pre-engine start tare corrections.

The strain-gage data are measured at 100 samples/sec, but unfortunately for the thrust calculation, the signal conditioning is ranged to read beyond normal flight operating limits in both the forward and aft directions. This range, required for structural loads monitoring, produces much less than optimum resolution for the mount-thrust measurement. Using a 10-bit instrumentation system, current data resolution for the prime thrust bridges is $58 \mathrm{lbf} /$ count. For a system optimized for positive thrust measurement, the data resolution is estimated to be as low as $15 \mathrm{lbf} /$ count. Ambient system noise prior to engine start is approximately 1 count. Combined with accelerometer noise feeding the inertia calculation, the mount-thrust data, even with the excessive ranging, has a relatively low root-mean-square noise band (less than $\pm 100 \mathrm{lbf}$ ).

\section{$\underline{\text { In-Flight Thrust Analysis }}$}

The strain-gage sensors installed on the engine mounts measure the engine force applied directly to the airframe (the mount thrust) and, therefore, measure a load that is more similar to net thrust than to gross thrust. Unfortunately, because of the manner in which propulsive forces are accounted for, net thrust, as it is defined, does not always resemble the applied force at the engine mounts, particularly at high speeds. To derive either net thrust or gross thrust from the direct thrust measurement, considering and accounting for all significant forces acting upon the engine directly and summing these forces as required with the direct value therefore becomes necessary. Figure 17 shows the typical array of forces acting upon an installed engine, as in the F-15 ACTIVE vehicle.

\section{Assumptions}

With the goal of this exercise being to compute gross thrust, several assumptions would obviously be required regarding the forces shown in figure 17, because many forces are immeasurable or were not instrumented for the ACTIVE program. For example, connector drag and aircraft interface rub are both unknown; however, steps were taken to minimize their effect so that they could be assumed equal to $0 \mathrm{lbf}$. In particular, connector drag was minimized by providing freedom of movement in the cabling and plumbing linking the airframe with the motor. The ACTIVE F-15 aircraft has a unique cinch strap system, used to tighten the aircraft titanium sealing flaps against the aft static structure of the nozzle. This system is believed to provide a balanced distribution between bay and ambient pressure which simplifies the gross thrust calculation as discussed later in this section.

No simple steps could be taken to ensure the elimination of inlet-seal reaction, but the seal design should accommodate a minimum of $0.25 \mathrm{in}$. of longitudinal deformation and thermal expansion of the



Figure 17. Forces acting upon an installed engine. 
engine. With no other recourse, inlet-seal reaction was therefore assumed equal to $0 \mathrm{lbf}$. As will be discussed, some evidence exists that indicates very high gross-thrust conditions may cause nonnegligible inlet-seal reaction, but only in a small portion of the flight envelope at maximum (full augmentation) power.

Nozzle drag is essentially an immeasurable force that is normally computed, as in the case of the F-15 airplane, using the airframe manufacturer's aircraft-engine installation effects model. The installation effects model also computes such variables as engine-bleed air and horsepower extraction. However, the model presents a large computational burden itself, and its use was not consistent with the goal of a reduced-complexity thrust calculation method using as input only measured data or data computed in real time onboard the aircraft.

Conveniently, nozzle drag is a negligible factor throughout much of the flight envelope at augmented power. However, with the smaller nozzle configurations at military (maximum nonaugmented) power and less, nozzle drag rises dramatically as speed approaches Mach 1. But gross thrust also rises rapidly as speed increases, so the effect on thrust of neglecting nozzle drag is minimized in percent terms. With this effect in mind, nozzle drag is assumed equal to $0 \mathrm{lbf}$ for this analysis. The effects of this assumption will be discussed in detail in the "Results and Discussion" section.

\section{Gross-Thrust Calculation}

The remainder of the force terms are nonnegligible; however, these terms can all be computed from the information available from the F-15 ACTIVE instrumentation data stream. As a result, gross thrust can now be calculated based upon the strain gage-based axial-force measurement at the engine mounts.

Summarizing the force terms shown in figure 17 and ignoring those terms assumed to equal zero in the above section, the following equation results:

$$
\begin{aligned}
F_{\text {gross }}= & F_{\text {mount }}+F_{\text {ram }}+F_{\text {face pressure }} \\
& -F_{\text {body pressure }}
\end{aligned}
$$

where $F_{\text {gross }}$ is gross thrust, $F_{\text {mount }}$ is the strain gage-based axial-force measurement at the engine mounts, $F_{r a m}$ is the engine inlet-plane ram-drag term caused by engine intake flow momentum, $F_{\text {face pressure }}$ is the drag caused by flow pressure on the engine face, and $F_{\text {body pressure }}$ is the resulting force acting on the aft-looking-forward projected area of the engine and includes the effects of ambient and engine-bay pressure. All forces are measured in units of lbf.

The projected area over which the inlet-face and nozzle-body pressure forces counteract each other is simplified by the assumption explained earlier that the engine-bay pressure is equal to ambient. As a result of this assumption, the face and body (ambient) pressures counteract each other over the exposed engine-inlet face cross-sectional area, $A_{\text {inlet }}$, and which is equal to 951.0 in $^{2}$ for the F100-series engine. Ambient pressure, $P_{0}$, is a position-corrected measurement available from the aircraft data stream. Engine inlet-face static pressure, $P_{2}$, is available as a production output of the IDEEC computer and is a spatially averaged measurement from the engine nosecone probe.

With $P_{0}$ and $P_{2}$ now known, the following equation can be constructed:

$$
\begin{gathered}
F_{\text {face pressure }}-F_{\text {body pressure }}= \\
A_{\text {inlet }} \cdot\left(P_{2}-P_{0}\right)
\end{gathered}
$$

where the inlet cross-sectional area is measured in units of $\mathrm{in}^{2}$ and the pressures are measured in units of $\mathrm{lbf} / \mathrm{in}^{2}$ absolute.

The engine inlet-plane ram-drag term, $F_{\text {ram }}$, is now the remaining unknown variable on the right side of equation 1. This variable is computed (as shown in the following equation) by multiplying true engine-inlet mass flow, $W A T_{2}$, in units of $1 \mathrm{bm} / \mathrm{sec}$ with engine inlet-plane velocity, $V_{2}$, in units of $\mathrm{f} / \mathrm{sec}$, both of which can be derived as shown below using output parameters from the IDEEC.

$$
F_{\text {ram }}=\frac{W A T_{2} \cdot V_{2}}{32.17}
$$

Engine mass flow is computed within the IDEEC because mass flow is an important parameter for control scheduling and stability management. However, the engine mass flow is output from the IDEEC in an engine station-corrected format and must be converted into true inlet mass flow to be usable for this application. This conversion is shown in the following equation:

$$
W A T_{2}=W A C C \cdot \frac{P_{T_{2}}}{14.70} \cdot\left(\frac{T_{T_{2}}+459.67}{518.67}\right)^{-0.5}
$$


where WACC is the IDEEC-estimated corrected mass flow measured in $\mathrm{lbm} / \mathrm{sec}, P_{T_{2}}$ is the IDEEC estimate of engine-inlet total pressure measured in $\mathrm{lbf} / \mathrm{in}^{2}$ absolute, and $T_{T_{2}}$ is the measured engine-inlet total temperature, also available from the IDEEC, measured in ${ }^{\circ} \mathrm{F}$.

Finally, $V_{2}$ is computed according to standard gas dynamic relationships as shown in the following two equations. First,

$$
V_{2}=V_{\text {sonic }} \cdot \mathbf{M}_{2}
$$

where $V_{\text {sonic }}$ is the sonic velocity in $\mathrm{ft} / \mathrm{sec}$ at the engine inlet, and $\mathrm{M}_{2}$ is the Mach number of the incoming flow. By expanding these terms and using the appropriate gas constant and specific heat ratio for air, the following equation can be derived:

$$
V_{2}=\sqrt{12014 \cdot\left(T_{T_{2}}+459.67\right) \cdot\left(1-\left(\frac{P_{T_{2}}}{P_{2}}\right)^{-0.286}\right)}
$$

where the engine-inlet plane velocity is now completely expressed in previously defined terms. Note that when equation 6 and equation 4 are used in equation 3 , the $T_{T_{2}}$ terms cancel.

All terms in equation 1 are now known, and gross thrust based upon the direct measurement at the engine mounts can be computed. Note that net thrust can easily be derived from the gross-thrust value by subtracting aircraft inlet-plane ram drag from equation 1. Aircraft inlet-plane ram drag is computed by multiplying true engine mass flow by the velocity of the aircraft.

Computing the engine inlet-plane ram-drag and pressure-force terms is not a complex matter provided that the required input parameters are readily available on the aircraft data stream, as in this case. Using the production data stream of a digital engine controller can therefore prevent the costly requirement to instrument the engine face in order to measure the temperatures and pressures necessary to calculate these force terms.

\section{Benchmark Analytical Model Descriptions}

Two analytically-based models supplied by Pratt \& Whitney were used to compute gross thrust in order to serve as benchmarks for the strain gage-based direct thrust-measurement technique. These models were the postflight aerothermodynamic thrust model and the onboard nozzle controller thrust model.

\section{Postflight Aerothermodynamic Thrust Model}

The postflight $\operatorname{model}^{8}$ is a high-fidelity aerothermodynamic simulation of the F100-PW-229 engine and is designed for customer use. A combination of engine performance modeling, engine component ground test data, and measured engine and aircraft flight data permit the model to accurately calculate thrust calculation using the mass flow-temperature method. ${ }^{9,} 10$ The use of measured engine parameters allows the model to partially compensate for engine-toengine performance variations. Measured values of free-stream altitude and Mach number, fan speed, fan guide-vane angle, turbine discharge total pressure, core and afterburner fuel flows, $P_{T_{2}}$, and $T_{T_{2}}$ were used as inputs to the model for this analysis. Free-stream altitude and Mach number were obtained from the flight controller, and the remainder of the parameters were obtained from the IDEEC. On some missions, high-accuracy, flight test, volumetric fuel flow meters were available and used in place of the IDEEC values.

An F-15 installation effects subroutine, developed by The Boeing Company (formerly McDonnell Douglas Aerospace), is used to account for airframe detriments to engine thrust performance, including horsepower and bleed air extraction. The combined engine-thrust and installation-effects modeling process is very computationally intensive and can require several hours on a dedicated computer workstation to process a single mission. The uncertainty band ${ }^{11}$ for calculated gross thrust from this model is estimated to range from 2 to 4 percent, depending on flight condition and power setting.

\section{Onboard Nozzle Controller Thrust Model}

A gross-thrust model residing within the nozzle controller onboard the F-15 ACTIVE aircraft is used to prevent the production of unsafe vector forces by the nozzle. This model was derived from the postflight model described in the above section and also uses measured data as input. However, this model uses simplified routines to speed the execution of the code, permitting its use in the real-time application but also increasing the uncertainty of the calculation.

The area-pressure thrust calculation method is used by the onboard model, which reduces the number of input parameters required to compute gross thrust. Nozzle 
throat area and turbine-discharge total pressure, both derived from the IDEEC, are used as input, along with $P_{0}$ from the flight controller. The reduced number of input parameters further increases the gross-thrust uncertainty relative to the postflight model because the area-pressure thrust calculation method tends to be more sensitive to input measurement error than the mass flow-temperature method.

The uncertainty band for this model is greater than for the postflight model; and the error increment grows as the engine departs from an average health state because the onboard model has less ability than the postflight model to accommodate off-nominal engine operation. Because of the critical role the onboard model plays in limiting the magnitude of the nozzle-vectoring forces in real time, an important objective of the ACTIVE program has been to validate the onboard gross-thrust model against the postflight model.

\section{Analysis Constraints and Scope}

For the purposes of this analysis, direct thrust-measurement data were processed only for quasi-steady-state aircraft and engine operation. The objective in doing so was to minimize the uncertainty in comparing the direct thrust-measurement technique against the reference models, which were designed for quasi-steady-state engine operation only. And although the strain-gage signal conditioning process has been designed to accommodate aircraft maneuvering and nozzle-vector forces, the effects of these forces on the engine-mount axial-force readings are still being quantified throughout the flight envelope and are not yet fully understood, as discussed previously.

As a result, the data were filtered to eliminate any time cuts with normal aircraft acceleration greater than $2 \mathrm{~g}$ and less than $0 \mathrm{~g}$, lateral acceleration greater than $0.1 \mathrm{~g}$, aircraft pitch rate greater than $2.5 \mathrm{deg} / \mathrm{sec}$, yaw rate greater than $2 \mathrm{deg} / \mathrm{sec}$, roll rate greater than $6 \mathrm{deg} / \mathrm{sec}$, pitch angle greater than $10^{\circ}$, roll angle greater than $20^{\circ}$, and climb rate greater than $50 \mathrm{ft} / \mathrm{sec}$. The data were also filtered for $6 \mathrm{sec}$ following any rapid throttle position change of more than $5^{\circ}$. All thrust data collected during nozzle vectoring or off-nominal exit area scheduling were also excluded by filtering.

This analysis focused on two throttle settings, military and maximum power, primarily because of the large quantity of data available at these two power settings throughout the ACTIVE flight envelope and because the reference models are considered most accurate at military and maximum power. Thirteen missions, spaced over an eight-month period in 1996, were selected because those missions most fully covered the flight envelope and offered a wealth of stabilized engine data from low to high Mach number. These missions were analyzed in their entirety, and their data were filtered according to the above constraints. The result was a data base of 3822 time cuts at military power and 1420 time cuts at maximum power.

Differences were computed between the direct thrust-measurement method values and the output from the reference models for each time cut of data. The data from all flights were combined for each power setting and then sorted based on Mach number and altitude into blocks, each spanning $5000 \mathrm{ft}$ and $0.1 \mathrm{Mach}$. The data for each parameter within each block were then averaged. At military power, 52 Mach-altitude blocks resulted; at maximum power, 58 blocks resulted. The large spread of the data throughout the flight envelope can be seen on the Mach-altitude cross plots in the "Results and Discussion" section. Scale references have been removed on absolute data to protect the proprietary nature of the information.

\section{$\underline{\text { Results and Discussion }}$}

Figure 18 shows the percent difference between military-power gross thrust computed using the direct thrust-measurement technique and gross thrust computed by the postflight model. The difference is plotted as a function of Mach number for a representative range of altitudes: $10,000 \mathrm{ft}, 20,000 \mathrm{ft}$, $30,000 \mathrm{ft}$, and 45,000 ft. The percent differences range from approximately 1 to 12 percent, depending on flight condition. At a given altitude, the difference tends to decrease as subsonic speed increases. This trend reverses prior to Mach 1.0, with the difference peaking near Mach 1.0 and then decreasing again as the speed increases. The average percent difference for all military-power points is 4.2 percent.

Figure 19 shows a similar arrangement of data as shown in figure 18 , except that the power setting is now at maximum. In this case, percent differences range between approximately 2 and 13 percent. The local peak in the percent differences seen in the vicinity of Mach 1 at military power is less clear at maximum power; however, a strongly decreasing trend is evident at an altitude of $45,000 \mathrm{ft}$ to a maximum speed of Mach 2.0. At an altitude of $30,000 \mathrm{ft}$, the percent difference is relatively stable as speed increases to a maximum of Mach 1.7, beyond which the difference abruptly rises and continues to do so until Mach 2.0 is reached. The average percent difference for all maximum-power points is 3.8 percent. 


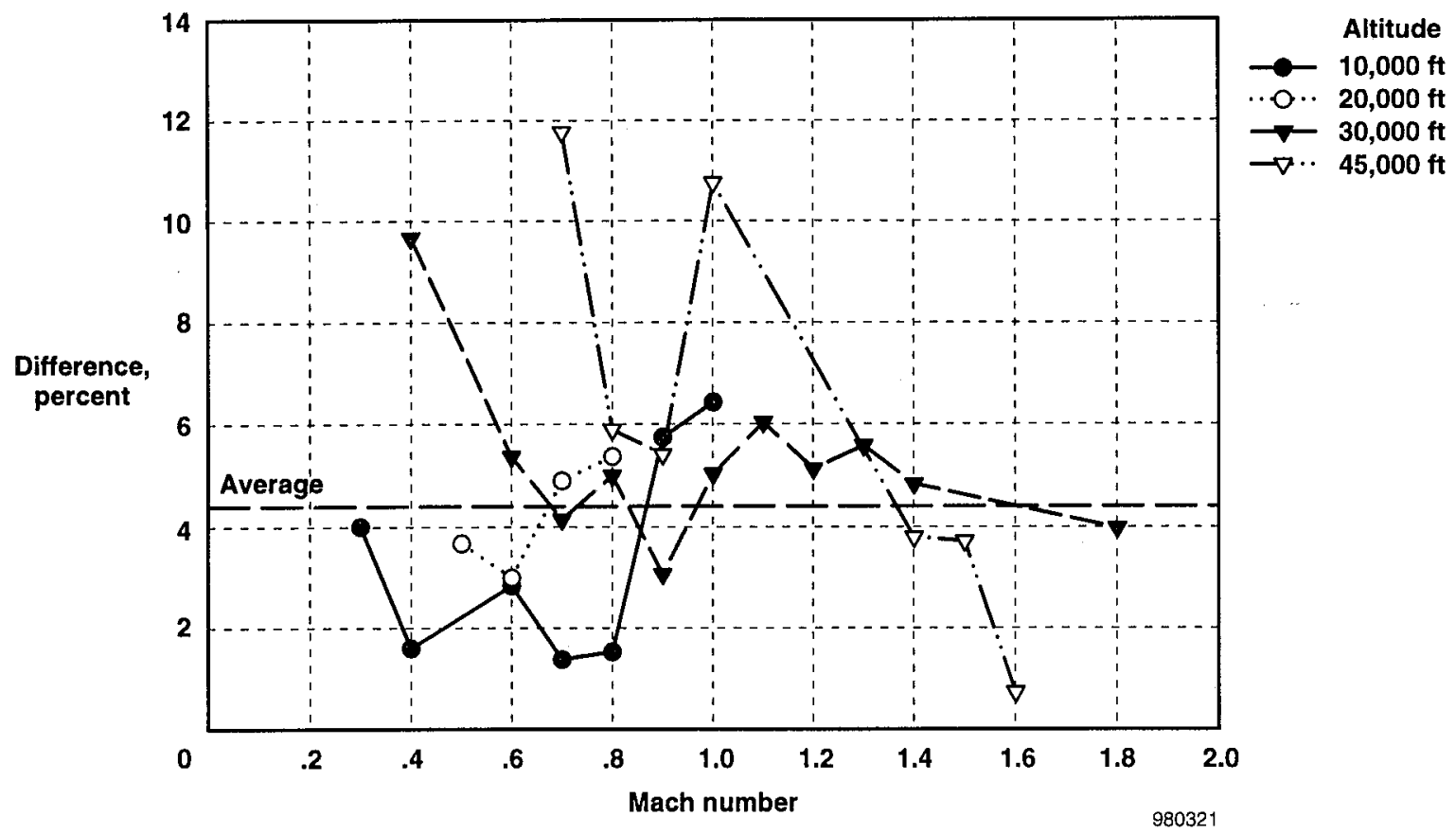

Figure 18. Percent difference in gross thrust between direct thrust-measurement technique and postflight model as a function of flight condition; military power.

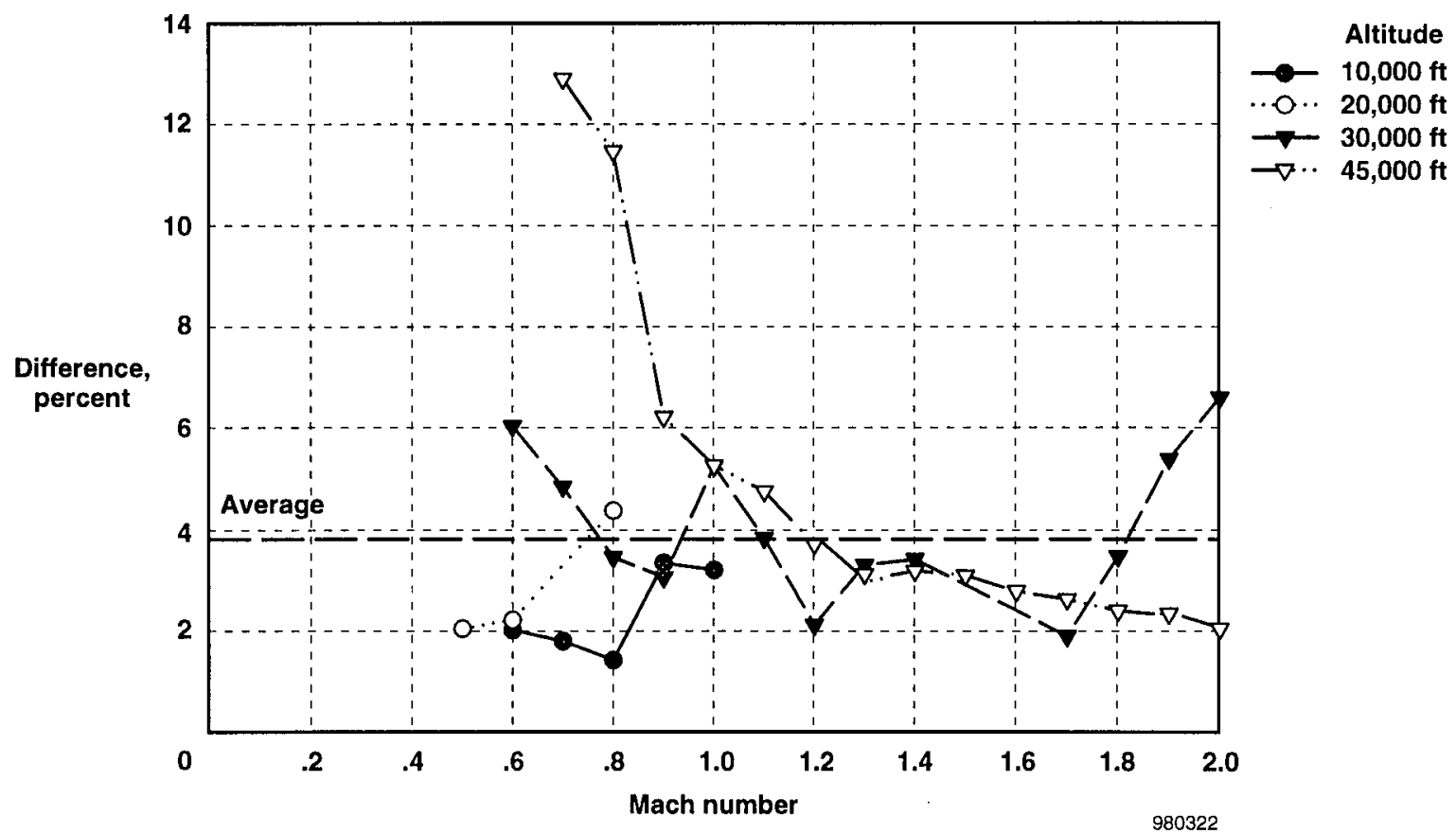

Figure 19. Percent difference in gross thrust between direct thrust-measurement technique and postflight model as a function of flight condition; maximum power. 
Figure 20 shows absolute differences in gross thrust at military power between the direct thrust-measurement technique and the postflight model. A sharp change in the difference occurs at Mach 0.8 and faster at altitudes of $10,000 \mathrm{ft}$ and 30,000 ft (no data exist for speeds greater than Mach 0.8 at an altitude of 20,000 ft).

At a given flight condition, nozzle drag is typically much higher at military power than it is at maximum power. This difference grows dramatically in the lower right-hand side of the flight envelope, and computer models indicate that nozzle drag can exceed $1000 \mathrm{lbf}$ at the highest dynamic pressures. At these flight conditions, nozzle drag at maximum power actually reverses through $0 \mathrm{lbf}$ as the large, outboard, divergent-section boat-tail angles combined with the large throat areas create a forward-acting force component. If these modeled nozzle-drag values are included in equation 1 for military power, the supersonic curves tend to match more closely with their subsonic counterparts at a given altitude. Regardless, the additional error caused by the exclusion of nozzle drag in equation 1 does not result in a correspondingly large percentage difference (as can be seen in figure 18) because as speed increases, so does gross thrust.

Figure 21 shows the absolute difference in gross thrust at maximum power between the direct thrustmeasurement technique and the postffight model. In this case, the differences tend to be somewhat stable with Mach number, with the exception that at Mach 1.8 and an altitude of 30,000 ft, a dramatic change occurs as Mach number increases. This event can also be seen in figure 19 in the same portion of the flight envelope. This sudden departure in the data occurs in the highest dynamic-pressure portion of the F-15 ACTIVE flight envelope where gross thrust is highest and engine thermal conditions are most severe. One possible cause is that the high gross-thrust values were combining with maximized thermal lengthening of the engine and thus flattened the engine inlet $\mathrm{J}$ flange against the $\mathrm{K}$-seal interface. With a new unquantifiable load path developing, the engine mounts experienced less load, and thus the difference between the direct thrust-measurement technique and the postflight model grew with speed.

As shown in figures 18 and 19 , the percent differences between the two techniques are somewhat high at altitudes of 30,000 ft and 45,000 ft and low Mach number conditions. But as figures 20 and 21 show, the absolute differences at these conditions do not stand out when compared with other flight conditions. Gross thrust rapidly decreases as the upper left-hand corner of the flight envelope is approached, and so the response in percentage difference is amplified there.



Figure 20. Absolute difference in gross thrust between direct thrust-measurement technique and postflight model as a function of flight condition; military power. 




Figure 21. Absolute difference in gross thrust between direct thrust-measurement technique and postflight model as a function of flight condition; maximum power.

Bubble plots are displayed on a Mach-altitude cross plot in figures 22 and 23 for the percent differences at military and maximum power, respectively, and in figures 24 and 25 for the absolute differences at military and maximum power, respectively. An outline of the flight envelope of the F-15 ACTIVE aircraft is also shown on each figure for reference. Whereas figures 18 to 21 show data trends at selected altitudes for the sake of clarity, figures 22 to 25 show all of the Mach-altitude averaged data and qualitatively show the trends in the data on the full flight envelope.

The size of each bubble is directly proportional to its value, and this proportionality is maintained from plot to plot. Of particular note are the high percentage differences seen in the upper left-hand corner of the flight envelope and the large absolute differences seen along the lower right-hand edge of the envelope, both previously discussed. Note the very small differences, both absolute and percent at each power setting, for the takeoff roll near sea level; some of the data point bubbles cannot be seen on the plots because the bubbles are smaller than the width of the flight envelope boundary.

Figure 26 shows gross thrust as a function of Mach number at an altitude of approximately $30,000 \mathrm{ft}$ for a maximum-power acceleration from Mach 0.75 to Mach 1.95 and the subsequent deceleration at military power. Gross thrust is shown for the direct thrust-measurement technique, the postflight model, and the onboard model. At speeds less than Mach 1.3 during deceleration, the engine is closer to idle power than it is to military power. This particular example illustrates the largest absolute difference seen in the data base between the direct measurement technique and the postflight model, which occurred at maximum power, a speed of Mach 1.95, and an altitude of 32,000 ft. This difference is possibly the result of inlet-seal reaction as discussed earlier. Despite this difference, the figure shows very good agreement between the direct thrust-measurement technique and the two models, especially considering the data span an enormous range of aircraft and engine operating conditions.

Note that the direct thrust-measurement technique shows very close agreement with the onboard model during the acceleration to a maximum speed of approximately Mach 1.6. In fact, as a general rule throughout the flight envelope, the onboard model tended to agree more closely with the direct thrust-measurement technique than with the postflight model. The average percent difference between the direct thrust-measurement technique and the onboard model was 2.2 percent for all military-power points and 1.2 percent for all maximum-power points. 


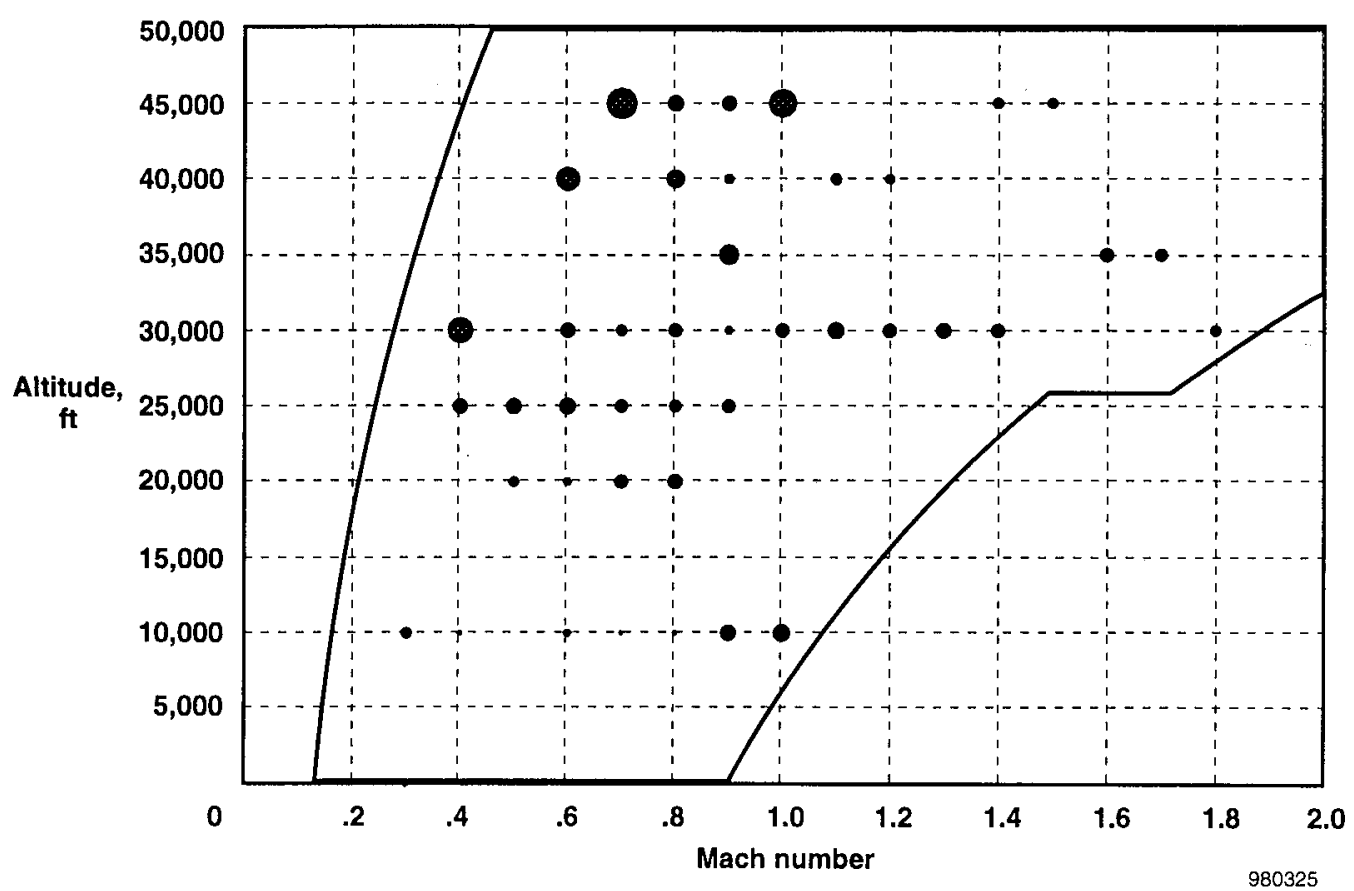

Figure 22. Relative change in percent difference in gross thrust between direct thrust-measurement technique and postflight model as a function of flight condition; military power.



Figure 23. Relative change in percent difference in gross thrust between direct thrust-measurement technique and postflight model as a function of flight condition; maximum power. 




Figure 24. Relative change in absolute difference in gross thrust between direct thrust-measurement technique and postflight model as a function of flight condition; military power.

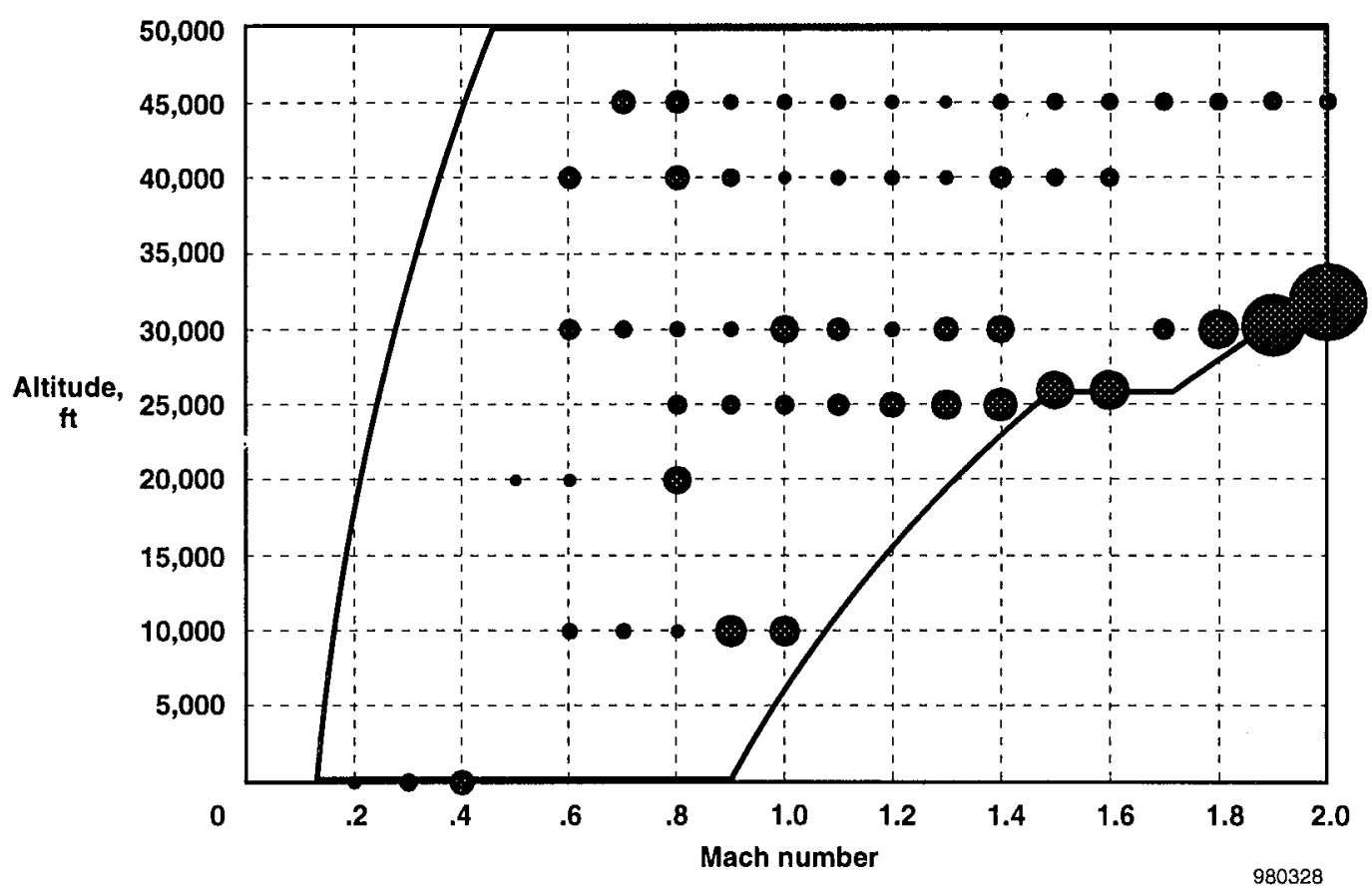

Figure 25. Relative change in absolute difference in gross thrust between direct thrust-measurement technique and postflight model as a function of flight condition; maximum power. 




Figure 26. Gross thrust calculation method comparison for a maximum-power acceleration and military-power deceleration at an altitude of approximately $30,000 \mathrm{ft}$.

The low-noise characteristics of the strain gage-based method is also evident in this figure. In fact, the standard deviation of the direct thrust-measurement technique tends to be as good as or slightly better than the analytical methods throughout the flight envelope at stabilized flight conditions.

Table 2 shows the bias and standard deviation of the direct thrust-measurement values relative to the results from the two analytical methods. From the data in the table, the vast majority of direct thrust-measurement data evidently falls below the postflight model at both power settings. This skew is currently under investigation, although obvious potential causes include unaccounted secondary forces and postflight model input data bias. The latter is thought to be likely because the direct thrust data are more equally distributed about the onboard model results, as the table shows.

As airspeed increases at a given altitude, the engine-pressure drag (eq. 2) reverses at approximately Mach 0.6 from a suction force that actually adds to net propulsive force to a true drag that grows exponentially with Mach number. At Mach 2.0 and an altitude of $30,000 \mathrm{ft}$, engine-pressure drag is approximately 50 percent of the maximum-power gross-thrust value; the percentage is even greater at military power. The changes in engine-face ram drag as a percentage of gross thrust are more gradual than engine-pressure drag throughout the flight envelope, decreasing slightly with

Table 2. Percent bias and standard deviation of the direct thrustmeasurement method relative to the two analytical methods; military and maximum power.

\begin{tabular}{cccccccc}
\hline \hline & & \multicolumn{2}{c}{ Postflight model } & & \multicolumn{2}{c}{ Onboard model } \\
\cline { 3 - 4 } \cline { 7 - 8 } Power setting & $\begin{array}{c}\text { Data points } \\
\text { analyzed }\end{array}$ & Bias & $\begin{array}{c}\text { Standard } \\
\text { deviation }\end{array}$ & & Bias & $\begin{array}{c}\text { Standard } \\
\text { deviation }\end{array}$ \\
\hline Military & 3822 & -4.22 & 3.61 & & -2.24 & 4.14 \\
Maximum & 1420 & -3.81 & 2.44 & & +1.16 & 2.11 \\
\hline \hline
\end{tabular}


Mach number, but nonetheless averaging approximately 30 percent of the gross-thrust value for military power and 14 percent at maximum power.

These results qualitatively imply that gross-thrust values as calculated by the direct thrust-measurement technique in equation 1 would be sensitive to significant error in the ram-drag and pressure terms, particularly at high speeds. Care should be taken in accounting for these forces.

\section{Concluding Remarks}

Gross thrust was successfully computed using a strain gage-based direct thrust-measurement technique applied to the NASA F-15 Advanced Control Technology for Integrated Vehicles (ACTIVE) aircraft powered by two F100-PW-229 engines. Results were obtained at quasi-steady-state conditions throughout the flight envelope of the vehicle using data collected during 13 missions spanning an eight-month period. More than 5200 time cuts of data were processed to produce the results in this report, representing a Mach range from 0.0 to 2.0 and altitudes from near sea level to higher than $45,000 \mathrm{ft}$. Both military and maximum augmented power settings were studied.

The strain-gage calibration process, described in this paper, was developed in support of the ACTIVE program. This process has established the feasibility of measuring engine main-mount loads and extracting the axial thrust at the mount. The methodology has evolved and benefited from four distinct ground tests: shear fixture loadings, on-aircraft hangar testing (engines not installed), thermal tests, and combined systems testing (engines installed and operating). Feeding results from each step forward to understand and minimize each source of error to the greatest extent possible has been fundamental. The approach for instrumenting and calibrating the pins presents certain challenges but offers some distinct advantages and options: the pins are amenable to either on- or off-aircraft load calibration, and the pins easily fit in an oven for thermal testing. In addition, installing the pins in another aircraft or test stand is an option unique to this approach.

Another important advantage is the direct interception of the engine-force reactions. No concern exists for the gages responding to strain induced by other forces. Among the potential problems anticipated, none has proven to be significantly detrimental to the thrust-measurement process. However, the influence of the engine-mount clamping flexibility and resulting gapping was not anticipated and has aggravated certain problems that would have otherwise been minor or nonexistent. Revised calibration equations are warranted to minimize the cross-axis errors and improve the primary force calculations.

Gross thrust computed using the direct measurement technique differed from results obtained using a postflight aerothermodynamic engine model by an average of 4.2 percent at military power and 3.8 percent at maximum power, all data considered. When compared against an onboard gross-thrust model within the nozzle controller, the differences averaged 2.2 percent at military power and 1.2 percent at maximum power. Outside of a local peak occurring at military power at approximately Mach 1.0, the percent difference tended to decrease as speed increased. Percent differences were highest in the upper left-hand corner of the flight envelope where gross-thrust values are small and the effect of absolute differences on percent is amplified.

Engine inlet-plane ram drag, engine inlet-plane pressure drag, and ambient-pressure force on the nozzle were the only secondary forces included in the process of transforming the engine-mount strain-gage measurements into gross thrust. These three forces were computed in a straightforward manner using information readily available on the digital aircraft and engine controller data buses. In fact, the direct use of the engine controller output eliminated the need for costly additional flight test instrumentation.

The engine pressure term rises exponentially with speed and can exceed 50 percent of the gross-thrust value at Mach 2.0. The engine-face ram-drag term accounted for an average of 30 percent of military-power gross thrust and 14 percent at maximum power. These large values for the percentages indicate their important role in the accurate calculation of gross thrust using the direct thrust-measurement technique, and care must be taken in accounting for these forces.

Other secondary forces were assumed to equal $0 \mathrm{lbf}$ because they could not be easily quantified and their effects were believed to be minimal for this application. These secondary forces included connector forces and inlet-seal reactions. Nozzle drag, a nonzero secondary force, was not included in the analysis, primarily because of the large computational burden required to calculate it. The use of a large analytical model was thought to be inconsistent with the objective here of a simplified approach to thrust calculation; and, in percent terms, the exclusion of nozzle drag from the calculation process had only a minor impact on the results. 
Sensor Installation and Calibration Process Recommendations

- Application of the methodology developed here should be evaluated on a case-by-case basis for a particular aircraft configuration; not all configurations would be amenable to the technique.

- A good portion of the calibration accuracy is attributed to the gage selection and high-precision installation relative to the load axes.

- Maintaining precise angular alignment of the pin relative to the mount and the load axes will always be critical.

- For future applications, an assessment of the value or necessity of conducting both a fixture loading test and a "cold loads-type" test would be advisable. If a high-fidelity calibration effort is performed with either test, performing both tests is probably not necessary. Either test requires custom hardware and test setup. If an off-aircraft fixture loading is more desirable, the setup and loading should replicate the real aircraft as much as feasible.

- The single most beneficial improvement for any future application on a similar configuration would be to increase the stiffness of the main-mount clamping structure. The benefits would be reduced engine deflections and simplified calibration of the mount adapter pins.

\section{Considerations for the Analysis Process}

- Simplifying assumptions regarding secondary force terms must be given careful thought prior to computing gross and net thrust using the direct thrust-measurement technique. Ignoring these force terms may be acceptable on one type of airframe installation but not on another. In the absence of an analytical thrust model with which to provide a reference check, using carefully selected sensors to flag unaccounted secondary load paths (should they develop) may be prudent. For instance, a longitudinal engine displacement transducer can be used to ensure that high-speed inlet-seal bottoming is not occurring on a buried-engine installation.

- The use of output data from the digital engine controller, if one is available, should be capitalized upon. Provided that high-rate dynamic-thrust measurement or extreme accuracy are not requirements, the use of this readily available information can save costs by eliminating unnecessary specialized flight test instrumentation.

- When the flight test program commences, and depending on the program duration, periodic in-flight tare readings of the direct thrustmeasurement technique against a reference model may be prudent to flag a need for strain-gage sensor recalibration. A simplified engine performance specification model would serve well in this capacity and need not be as sophisticated as the postflight model described in this report.

\section{Proposed Additional Analyses}

Several additional analyses are proposed to further document the utility of the direct thrust-measurement technique:

- Collect additional data in those parts of the flight envelope where data are scarce.

- Improve the accuracy of the strain-gage calibration equations during all-axis maneuvering and thrust vectoring.

- Analyze the sensitivity to errors in input parameters and in the calculation and rejection of secondary forces.

- Fully quantify the accuracy below military power, particularly for cruise power settings.

- Investigate reducing bias error by using an appropriate correlation parameter readily available on the engine data bus.

- Increase the accuracy of the benchmark analytical models by maximizing the accuracy of their input parameters.

- Study the benefit of including a simple table lookup for nozzle drag in order to reduce high-speed thrust error.

- Determine if high-speed inlet-seal bottoming is an issue on the F-15 airplane by analyzing longitudinal engine displacement at the engine face.

- Study the accuracy stability of the engine-mount strain gages over long periods of time.

- Document the capability and limitations for high-response and dynamic-thrust calculation.

- Fully quantify the standard deviation and error bands against the analytical methods. 


\section{$\underline{\text { References }}$}

${ }^{1}$ Society of Automotive Engineers, Incorporated, Committee E-33, "In-Flight Thrust Determination," SAE-AIR-1703, Nov. 1985.

${ }^{2}$ Ray, Ronald J., Evaluating the Dynamic Response of In-Flight Thrust Calculation Techniques During Throttle Transients, NASA TM-4591, 1994.

${ }^{3}$ Groth, Harold W., Nick E. Samanich, and Philip Z. Blumenthal, Inflight Thrust Measuring System for Underwing Nacelles Installed on a Modified F-106 Aircraft, NASA TM-X-2356, 1971.

${ }^{4}$ Fogg, Alan, "Direct Measurement of In-Flight Thrust for Aircraft Engines," Proceedings of the Thirteenth Annual Symposium, Society of Flight Test Engineers, Sept. 1982, pp. 33-41.

${ }^{5}$ Smolka, James W., et al, "F-15 ACTIVE Flight Research Program," Fortieth Symposium Proceedings, Society of Experimental Test Pilots, Sept. 1996, pp. 112-145.
${ }^{6}$ Doane, P., R. Bursey, and G. Schkolnik, "F-15 ACTIVE: A Flexible Propulsion Integration Testbed," AIAA-94-3360, June 1994.

${ }^{7}$ McDonnell Aircraft Company, "STOL/Maneuver Technology Demonstrator: Volume 4, Axisymmetric Flight Test Report," WL-TR-91-3083, Sept. 1991.

${ }^{8}$ United Technologies Pratt \& Whitney, "F100-PW-229 Status Simulation With P/Y BBN Vectoring Capability: User's Manual for CCD 1430-00.0," FR-20248-26, Dec. 1994.

${ }^{9}$ Burcham, Frank W., Jr., An Investigation of Two Variations of the Gas Generator Method to Calculate the Thrust of the Afterburning Turbofan Engines Installed in an F-111A Airplane, NASA-TN-D-6297, 1971.

${ }^{10}$ Conners, Timothy R., Measurement Effects on the Calculation of In-Flight Thrust for an F404 Turbofan Engine, NASA TM-4140, 1989.

${ }^{11}$ Society of Automotive Engineers, Incorporated, Committee E-33, "Uncertainty of In-Flight Thrust Determination," SAE-AIR-1678, Aug. 1985. 
Public reporting burden for this collection of information is estimated to average 1 hour per response, including the time tor reviewing instructions, searching existing data sources, gathering and maintaining the date needed, and completing and reviewing the collection of information. Send comments regarding this burden estimate or any other aspect of this collection of information, including suggestions for reducing this burden, to Washington Headquarters Services. Directorate for information Operations and Reports, 1215 Jefferson Davis Highway, Suite 1204 , Arlington, VA 22202-4302, and to the Office of Management and Budget, Paperwork Peduction Project (0704-0188), Washington, DC 20503.

\begin{tabular}{|l|l|l|}
\hline 1. AGENCY USE ONLY (Leave blank) & $\begin{array}{l}\text { 2. REPORT DATE } \\
\text { July } 1998\end{array}$ & $\begin{array}{l}\text { 3. REPORT TYPE AND DATES COVERED } \\
\text { Technical Memorandum }\end{array}$ \\
\hline
\end{tabular}

4. TITLE AND SUBTITLE

5. FUNDING NUMBERS

Full Flight Envelope Direct Thrust Measurement on a Supersonic Aircraft

6. AUTHOR(S)

WU 529-20-04-00-33-00-MGT

Timothy R. Conners and Robert L. Sims

7. PERFORMING ORGANIZATION NAME(S) AND ADDRESS(ES)

NASA Dryden Flight Research Center

P.O. Box 273

Edwards, California 93523-0273

9. SPONSORING/MONITORING AGENCY NAME(S) AND ADDRESS(ES)

10. SPONSORING/MONITORING AGENCY REPORT NUMBER

National Aeronautics and Space Administration

Washington, DC 20546-0001

NASA/TM-1998-206560

11. SUPPLEMENTARY NOTES

Presented at the 34th AIAA/ASME/SAE/ASEE Joint Propulsion Conference, Cleveland, Ohio, July 13-15, 1998.

12a. DISTRIBUTION/AVAILABILITY STATEMENT

12b. DISTRIBUTION CODE

Unclassified-Unlimited

Subject Category 05

\section{ABSTRACT (Maximum 200 words)}

Direct thrust measurement using strain gages offers advantages over analytically-based thrust calculation methods. For flight test applications, the direct measurement method typically uses a simpler sensor arrangement and minimal data processing compared to analytical techniques, which normally require costly engine modeling and multisensor arrangements throughout the engine. Conversely, direct thrust measurement has historically produced less than desirable accuracy because of difficulty in mounting and calibrating the strain gages and the inability to account for secondary forces that influence the thrust reading at the engine mounts. Consequently, the strain-gage technique has normally been used for simple engine arrangements and primarily in the subsonic speed range. This paper presents the results of a strain gage-based direct thrustmeasurement technique developed by the NASA Dryden Flight Research Center and successfully applied to the full flight envelope of an F-15 aircraft powered by two F100-PW-229 turbofan engines. Measurements have been obtained at quasi-steady-state operating conditions at maximum nonaugmented and maximum augmented power throughout the altitude range of the vehicle and to a maximum speed of Mach 2.0, and are compared against results from two analytically-based thrust calculation methods. The strain-gage installation and calibration processes are also described.

14. SUBJECT TERMS

Accuracy, Analytical models, Calibration, Direct thrust measurement, F-15, F100-PW-229 engine, Strain gage, Supersonic, Thrust calculation

\begin{tabular}{|c|c|c|}
\hline $\begin{array}{l}\text { 17. SECURITY CLASSIFICATION } \\
\text { OF REPORT }\end{array}$ & $\begin{array}{l}\text { 18. SECURITY CLASSIFICATION } \\
\text { OF THIS PAGE }\end{array}$ & $\begin{array}{l}\text { 19. SECURTY CLASSIFICATION } \\
\text { OF ABSTRACT }\end{array}$ \\
\hline Unclassified & Unclassified & Unclassified \\
\hline
\end{tabular}

15. NUMBER OF PAGES 37

16. PRICE CODE A03

20. LIMITATION OF ABSTRACT Unlimited 